\title{
The prion protein protease sensitivity, stability and seeding activity in variably protease sensitive prionopathy brain tissue suggests molecular overlaps with sporadic Creutzfeldt-Jakob disease
}

\author{
Alexander H Peden ${ }^{*}$, Deep P Sarode, Carl R Mulholland, Marcelo A Barria, Diane L Ritchie, James W Ironside \\ and Mark W Head
}

\begin{abstract}
Introduction: Variably protease sensitive prionopathy (VPSPr) is a recently described, sporadic human prion disease that is pathologically and biochemically distinct from the currently recognised sporadic Creutzfeldt-Jakob disease $(s C J D)$ subtypes. The defining biochemical features of the abnormal form of the prion protein $\left(\operatorname{PrP}{ }^{S C}\right)$ in $V P S P r$ are increased sensitivity to proteolysis and the presence of an $\mathrm{N}$ - and C-terminally cleaved $\sim 8 \mathrm{kDa}$ protease resistant $\operatorname{Pr} \mathrm{P}^{\mathrm{Sc}}$ $\left(\mathrm{PrP}^{\mathrm{res}}\right.$ ) fragment. The biochemical and neuropathological profile of VPSPr has been proposed to resemble either Gerstmann-Sträussler-Scheinker syndrome (GSS) or familial CJD with the PRNP-V180I mutation. However, in some cases of VPSPr two protease resistant bands have been observed in Western blots that co-migrate with those of type 2 PrPres, suggesting that a proportion of the PrPSC present in VPSPr has properties similar to those of SCJD.

Results: Here, we have used conformation dependent immunoassay to confirm the presence of PrPSc in VPSPr that is more protease sensitive compared with SCJD. However, CDI also shows that a proportion of PrPSC in VPSPr resists PK digestion of its C-terminus, distinguishing it from GSS associated with $\sim 8 \mathrm{kDa}$ PrPres, and showing similarity to sCJD. Intensive investigation of a single VPSPr case with frozen tissue from multiple brain regions shows a broad, region-specific spectrum of protease sensitivity and differential stability of $\operatorname{PrP}^{\mathrm{Sc}}$ in the absence of PK treatment. Finally, using protein misfolding cyclic amplification and real-time quaking induced conversion, we show that VPSPr PrPSc has the potential to seed conversion in vitro and that seeding activity is dispersed through a broad range of aggregate sizes. We further propose that seeding activity is associated with the $\sim 19$ and $\sim 23 \mathrm{kDa}$ PrPres rather than the $\sim 8 \mathrm{kDa}$ fragment.
\end{abstract}

Conclusions: Therefore, PrPSc in VPSPr is heterogeneous in terms of protease sensitivity and stability to denaturation with the chaotrope $\mathrm{GdnHCl}$ and includes a proportion with similar properties to that found in SCJD.

Keywords: Variably protease resistant prionopathy, VPSPr, Prion, PrP, PrP ${ }^{\mathrm{SC}}$, Gerstmann-Sträussler-Scheinker syndrome (GSS), PMCA, RT-QulC

\footnotetext{
* Correspondence: A.Peden@ed.ac.uk

National CJD Research \& Surveillance Unit (NCJDRSU), School of Clinical Sciences (Division of Clinical Neurosciences), College of Medicine and Veterinary Medicine, University of Edinburgh, Western General Hospital, Crewe Road, Edinburgh EH4 2XU, UK
}

\section{() Biomed Central}

(c) 2014 Peden et al.; licensee BioMed Central Ltd. This is an Open Access article distributed under the terms of the Creative Commons Attribution License (http://creativecommons.org/licenses/by/4.0), which permits unrestricted use, distribution, and reproduction in any medium, provided the original work is properly credited. The Creative Commons Public Domain Dedication waiver (http://creativecommons.org/publicdomain/zero/1.0/) applies to the data made available in this article, unless otherwise stated. 


\section{Introduction}

Human prion diseases are invariably fatal neurodegenerative disorders that include sporadic, genetic and acquired forms. The phenotypic and strain-related properties of human prion diseases are, according to the prion hypothesis, enciphered in the conformation of the misfolded, disease associated isoform of the prion protein, $\mathrm{PrP}^{\mathrm{Sc}}$ (Table 1), which is partially protease resistant and accumulates in the brains of patients with disorders such as Creutzfeldt-Jakob disease and Gerstmann-Sträussler-Scheinker syndrome (GSS). Molecular strain typing has focused extensively on differences in the fragment size and glycosylation site occupancy of $\operatorname{Pr} \mathrm{P}^{\text {res }}$, the proteinase resistant core of $\operatorname{Pr} \mathrm{P}^{\mathrm{Sc}}$ (Table 1) resulting from limited digestion with proteinase $\mathrm{K}(\mathrm{PK})$. Although defined by clinico-pathological criteria, different subtypes of human prion disease can be classified using these $\mathrm{PrP}^{\mathrm{res}}$ molecular profiles in conjunction with the presence of mutations and polymorphisms in the prion protein gene (PRNP). For example, in sporadic CJD (sCJD) six molecular subtypes have been defined that combine the PRNP codon-129 genotype polymorphism (MM, MV or VV) with the apparent molecular mass of the unglycosylated protease resistant fragment of $\operatorname{PrP}^{\text {res }}$ on western blots which is either $21 \mathrm{kDa}$ (type 1) or $19 \mathrm{kDa}$ (type 2A), according to the nomenclature of Parchi and Gambetti [1]. In addition, other $\operatorname{PrP}^{\mathrm{Sc}}$ fragment sizes have been noted in association with other human prion diseases, e.g. GSS with the P102L mutation in PRNP, in which either type $1 \mathrm{PrP}^{\text {res }}$ or a low molecular mass $\sim 8 \mathrm{kDa} \mathrm{PrP}^{\text {res }}$ fragment can predominate [2].

Variably protease-sensitive prionopathy (VPSPr) is a novel sporadic human prion disease that was first reported in the USA in 2008 [3]. Further cases of VPSPr have been identified prospectively and retrospectively in the USA [4], UK [5-7], the Netherlands [8] and Spain $[9,10]$. VPSPr has a distinctive neuropathology characterised by the presence of microplaques, but it is essentially defined by the biochemistry of $\operatorname{PrP}^{\mathrm{Sc}}$ in the brain that is less resistant to proteases than the $\operatorname{PrP}^{\mathrm{Sc}}$ in other human prion diseases, and the presence of $\mathrm{N}$ - and C-terminally cleaved $\sim 8 \mathrm{kDa}$ $\mathrm{PrP}^{\mathrm{res}}$. In these respects VPSPr has been proposed to resemble GSS $[4,8]$, although a comparison has also been drawn with familial CJD associated with the V180I-129 M haplotype, with respect to the absence of diglycosylated $\operatorname{PrP}^{\text {res }}$ and the presence of $\sim 8 \mathrm{kDa} \operatorname{PrP}^{\text {res }}$ [11]. Alternatively, we and others have identified regional heterogeneity in the PrP ${ }^{\text {res }}$ profile in some VPSPr brains, specifically the presence of bands with mobilities very similar to type $2 \mathrm{~A}$ $\mathrm{PrP}^{\text {res }}$ in VPSPr cerebellum, an observation that suggests that a proportion of the $\mathrm{PrP}^{\mathrm{Sc}}$ present has properties similar to those found in SCJD [3,7,10].

In this paper, we have employed conformation dependent immunoassay (CDI), to characterise the physicochemical properties of $\operatorname{PrP}^{\mathrm{Sc}}$ in VPSPr brain. CDI can sensitively detect both protease-sensitive $\operatorname{PrP}^{\mathrm{Sc}}\left(\right.$ senPrP $\left.{ }^{\mathrm{Sc}}\right)$ and protease resistant $\operatorname{PrP}^{\mathrm{Sc}}\left(\mathrm{PrP}^{\mathrm{res}}\right)$ with intact $\mathrm{C}$-termini, and can measure the conformational stability of $\operatorname{PrP}^{\mathrm{Sc}}$ isoforms to guanidine denaturation when no PK is used. CDI detects $\operatorname{PrP}^{\mathrm{Sc}}$ on the basis of an increase in signal following denaturation with guanidine $\mathrm{HCl}$, because epitopes hidden within the structure of $\mathrm{PrP}^{\mathrm{Sc}}$ become exposed in the presence of this chaotropic salt. In practice, for CDI to efficiently detect $\operatorname{PrP}^{\mathrm{Sc}}$ a preparative step, such as NaPTA precipitation, mild proteolysis $(\leq 2.5 \mu \mathrm{g} / \mathrm{ml} \mathrm{PK})$ or centrifugal concentration is usually necessary, in order to remove $\operatorname{PrP}^{C}[12-14]$. We have performed the above analyses comparing VPSPr to SCJD and GSS focussing on aspects of the regional variability of $\mathrm{PrP}^{\mathrm{Sc}}$ in terms of protease resistance and stability. These analyses have been done in order to aid our understanding

\section{Table 1 Abbreviations used throughout}

\begin{tabular}{|c|c|}
\hline Abbreviation & Definition \\
\hline $\operatorname{PrP}^{\mathrm{SC}}$ & $\begin{array}{l}\text { The abnormal, disease-associated form (generically termed the scrapie isoform, irrespective of the } \\
\text { disease and species in which it occurs) which is characterised by increased } \beta \text {-pleated sheet content, } \\
\text { decreased solubility and increased protease-resistance compared with PrPC as a result of refolding of } \\
\text { the protein and self-aggregation. }\end{array}$ \\
\hline $\operatorname{PrP}{ }^{C}$ & Normal form of the prion protein as expressed in the central nervous system and other tissues. \\
\hline Prpres & Protease resistant core of $\mathrm{PrP} \mathrm{P}^{\mathrm{Sc}}$ detected by western blotting following treatment with $50 \mathrm{\mu g} / \mathrm{ml} \mathrm{PK}$. \\
\hline$\sim 8 \mathrm{kDa}$ PrPres fragment & $\begin{array}{l}\text { Low molecular mass PrPres fragment of } \sim 8 \mathrm{kDa} \text { detected by western blotting following treatment } \\
\text { with } 50 \mathrm{\mu g} / \mathrm{ml} \text { PK in brain tissue from patients with VPSPr and some patients with GSS. }\end{array}$ \\
\hline senPrP ${ }^{S C}$ & The component of $\mathrm{PrP}^{\mathrm{SC}}$ that is poorly resistant to protease treatment (i.e. $>2.5 \mu \mathrm{g} / \mathrm{ml} \mathrm{PK}$ ) \\
\hline CDI & Conformation dependent immunoassay \\
\hline GSS & Gerstmann-Sträussler-Scheinker syndrome \\
\hline GSS ( 8 kDa PrPres) & $\begin{array}{l}\text { GSS case associated with a low molecular mass fragment of PrPres of approximately } \sim 8 \mathrm{kDa} \text { when } \\
\text { analysed by western blotting following proteinase } \mathrm{K} \text { digestion. }\end{array}$ \\
\hline GSS (type 1 Prpres) & $\begin{array}{l}\text { GSS case characterised by the presence of } 20-30 \mathrm{kDa} \text { type } 1 \text { PrPres fragments in brain when analysed } \\
\text { by western blotting following proteinase K digestion. }\end{array}$ \\
\hline
\end{tabular}


of the distinction of VPSPr from other prion diseases at the molecular level. We have also investigated whether there are any regional differences in the way VPSPr PrP $\mathrm{P}^{\mathrm{Sc}}$ behaves in a cell-free conversion assay, protein misfolding cyclic amplification (PMCA). Having previously shown that brain homogenates of all sCJD subtypes can efficiently seed real-time quaking induced conversion (RT-QuIC) at levels equivalent to femto grams $\left(1 \times 10^{-15} \mathrm{~g}\right)$ of $\mathrm{PrP}^{\mathrm{res}}$, we also compared the seeding potential of differently sized $\mathrm{PrP}^{\mathrm{Sc}}$ aggregates in VPSPr and sCJD by RT-QuIC [15].

\section{Materials and methods}

\section{Tissues used in this study}

This study was limited by the availability of frozen tissue with consent for research from VPSPr cases. We have identified nine cases of VPSPr in total over the surveillance period 1991-present, disproportionately affecting individuals who are VV at PRNP codon-129. Table 2 summarises the frozen tissue available for this study. No MM cases and only one MV case had frozen tissue available for research. In only one of the four VV cases (case 1) was a complete half brain taken at autopsy with consent for research.

In addition, three sporadic Creutzfeldt-Jakob disease (sCJD) cases (MM1, MM2 and VV2 subtypes), one variant CJD case (vCJD), two Gerstmann-Straüssler-Scheinker disease (GSS) cases (both P102L mutation), and 10 control (non-prion disease) cases were analysed in this study. Five of the latter control cases, from the MRC Edinburgh CJD Brain and Tissue bank, had been considered for a clinical diagnosis of human prion disease, but an alternative pathological diagnosis was reached. The other five cases, from the MRC Sudden Death Brain and Tissue bank, had no neurological or neuropathological evidence of disease. All cases used were of UK origin. The tissues were collected with consent for research, and the study was conducted under research ethics approval (11/ES/0022, Edinburgh Brain Bank).

\section{Immunohistochemistry}

VPSPr cases in this study were reviewed by immunohistochemical analysis for PrP using the anti-PrP antibodies
3F4, 12F10, KG9 and 6H4 as described previously [7]. A semi-quantitative estimation was made on the relative density of microplaques within the molecular layer of the cerebellum in all five cases of VPSPr using the 3F4 antibody; sections were reviewed independently by two experienced reviewers (DLR, JWI) using a four point scale with 0 being absent and $3+$ being severe (see Table 2 ).

\section{Homogenization of brain samples for conformation dependent immunoassay (CDI) analysis}

Frozen tissue samples were weighed and homogenised in phosphate buffered saline containing $2 \% N$-lauroylsarcosine, to a final tissue concentration of $10 \%$ (wt/vol) using a Fastprep machine (MP Biomedical, CA, USA) as described by us previously [12]. The homogenates were then cleared of cellular debris by centrifugation at $5200 \mathrm{~g}$ for five minutes at $4^{\circ} \mathrm{C}$.

\section{Detection of $\operatorname{PrP}^{\mathrm{Sc}}$ by $\mathrm{CDI}$}

We used a 96-well plate based conformation-dependent immunoassay (CDI) to characterise the physicochemical properties of $\mathrm{PrP}^{\mathrm{Sc}}$ in VPSPr and the controls mentioned above. The CDI method used has been described previously [13]. CDI resembles a sandwich ELISA but it involves a capture antibody, MAR-1, which binds both the native and denatured forms of the normal prion protein, $\operatorname{PrP}^{\mathrm{C}}$ (Table 1), and the abnormal, disease-associated prion protein, $\operatorname{PrP}^{\mathrm{Sc}}$. However, the detection antibody (europium-labelled 3F4) binds both native and denatured $\operatorname{PrP}^{\mathrm{c}}$, but only binds to $\operatorname{PrP}^{\mathrm{Sc}}$ after it has been denatured by guanidine hydrochloride $(\mathrm{GdnHCl})$. Therefore, the signal detected when the sample is denatured (D) minus the signal for the native samples $(\mathrm{N})$ can be used as a quantitative measure of $\operatorname{PrP}^{\mathrm{Sc}}$.

For $\mathrm{PrP}^{\mathrm{Sc}}$ to be detected by CDI, the MAR-1 and 3F4 epitopes must be intact and not subject to proteolytic processing in either conformer. Due to the position of the MAR-1 capture epitope, only $\operatorname{PrP}^{\mathrm{Sc}}$ with an intact C-terminus is detectable by CDI (Figure 1a). The $\sim 8 \mathrm{kDa}$ fragment observed in VPSPr by western blot following proteinase $\mathrm{K}$ digestion (Figure $1 \mathrm{~b}$ ) lacks that $\mathrm{C}$-terminal epitope for the MAR-1 antibody and is undetectable by

Table 2 Summary of the five VPSPr cases used in this study

\begin{tabular}{llll}
\hline $\begin{array}{l}\text { VPSPr case number } \\
\text { (in this study) }\end{array}$ & $\begin{array}{l}\text { PRNP-codon } \\
\mathbf{1 2 9} \text { genotype }\end{array}$ & References & $\begin{array}{l}\text { Frozen tissues available } \\
\text { (Abbreviations as in Figure 5.) }\end{array}$ \\
\hline 1 & W & $\begin{array}{l}\text { Semi-quantitative score for the } \\
\text { presence of microplaques in the } \\
\text { cerebellum } \mathbf{0}=\text { absent } \mathbf{3 +}=\text { severe }\end{array}$ \\
2 & This study & $\begin{array}{l}\text { FC, TC, PC, OC, Cb, Hip,Thal, } \\
\text { Midbrain, Pons, Me }\end{array}$ \\
3 & W & [7] (Case 4) & FC, Cb \\
4 & [7] (Case 3) & FC, Cb, TC \\
5 & WV & FC, Cb & FC \\
\hline
\end{tabular}




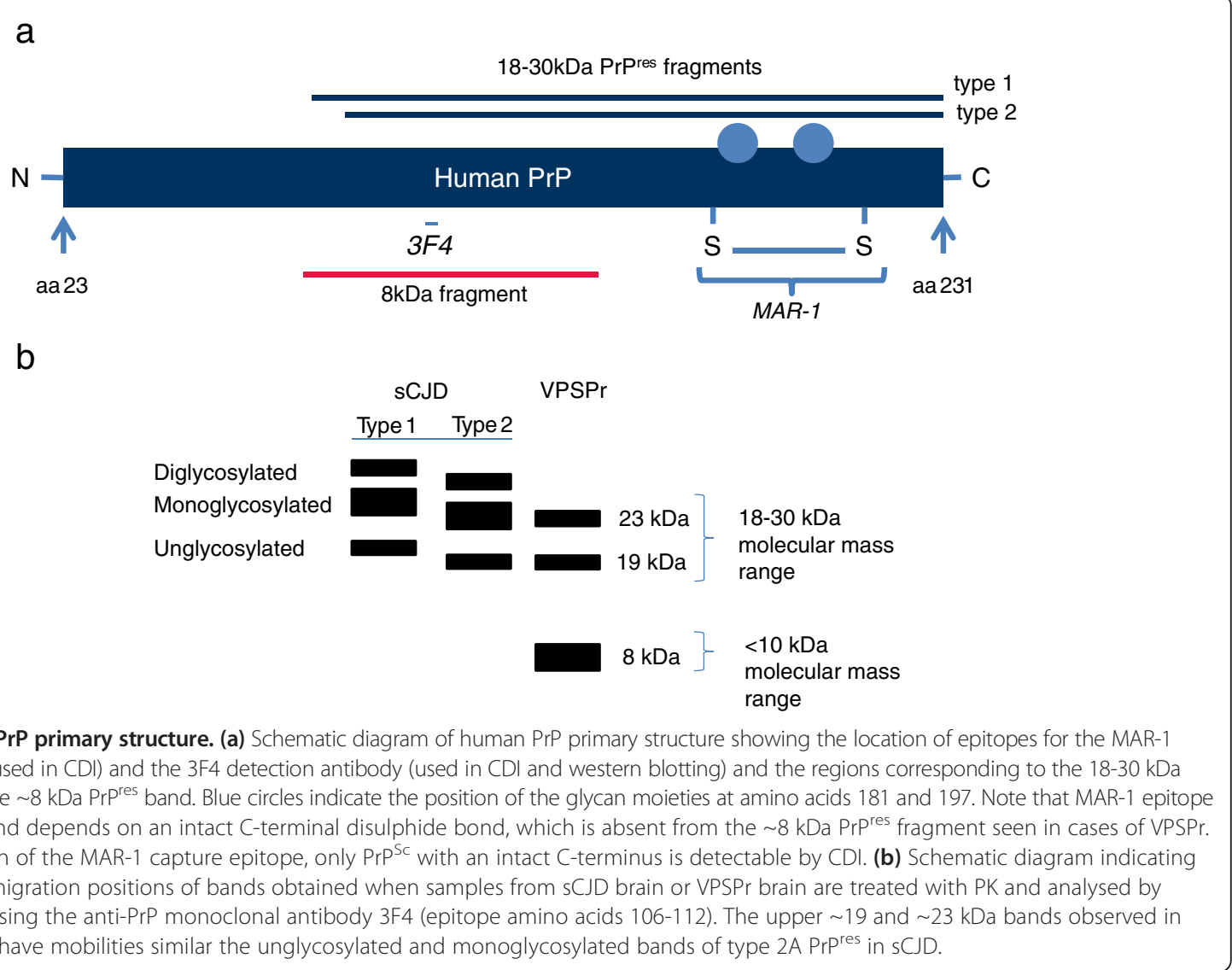

CDI. However, the bands observed in some brain regions from some VPSPr cases at $\sim 19$ and $\sim 23 \mathrm{kDa}$ which may directly correspond to the mono- and unglycosylated bands of sCJD with type $2 \operatorname{PrP}^{\text {res }}$ (Figure $1 \mathrm{~b}$ ) are detectable using antibodies that recognise $\mathrm{C}$-terminal epitopes in $\operatorname{PrP}$ (Additional file 1: Figure S1). Therefore, these protease resistant fragments may be detectable by CDI.

Homogenates $(10 \% \mathrm{w} / \mathrm{v})$ from all tissues used in this study (see above) were either assayed by CDI directly, or following limited proteolytic digestion with $1,2.5,10$ or $50 \mu \mathrm{g} / \mathrm{ml}$ PK for $1 \mathrm{~h}$ at $37^{\circ} \mathrm{C}$. PK digestion was terminated by the addition of $1 \mathrm{mM}$ Pefabloc SC. Homogenates were divided into two equal aliquots. One aliquot was mixed with an equal volume of $8 \mathrm{M}$ guanidine hydrochloride $(\mathrm{GdnHCl})$ and denatured (D) by incubating at $81^{\circ} \mathrm{C}$ for six minutes and the other was diluted without $\mathrm{GdnHCl}$ and left at room temperature and designated native $(\mathrm{N})$. The remainder of the CDI method used in this study was performed as described previously [13] using the dissociation enhanced lanthanide fluorescence immunoassay technology (DELFIA ${ }^{\mathrm{tm}}$, PerkinElmer, Cambridge, $\mathrm{UK})$. Both $\mathrm{D}$ and $\mathrm{N}$ samples were adjusted to a final volume of $650 \mu \mathrm{l}$ and a final guanidine concentration of $308 \mathrm{mM}$, with water containing complete ${ }^{\mathrm{Tw}}$ EDTA-free protease inhibitors (Roche, Hertfordshire, UK). The
anti-PrP capture antibody MAR-1 (a generous gift from Dr Albrecht Gröner, CSL Behring, Marburg, Germany) was used at $0.5 \mu \mathrm{g} /$ well. The wells were washed with DELFIA wash buffer (PerkinElmer). After saturating the plate by shaking for $1 \mathrm{~h}$ with $0.5 \%$ (wt/vol) bovine serum albumin and 6\% D-sorbitol (wt/vol) in DELFIA wash buffer, the wells were washed and the $\mathrm{D}$ or $\mathrm{N}$ samples were loaded in triplicate onto the plate $(200 \mu \mathrm{l} /$ well $)$ and incubated for $2 \mathrm{~h}$ at $20^{\circ} \mathrm{C}$ with shaking.

After washing the plate, europium-conjugated anti-PrP antibody 3F4 $(\sim 25 \mathrm{ng} / \mathrm{ml})$ in DELFIA assay buffer (200 $\mu \mathrm{l} /$ well) was added to all wells and incubated for $2 \mathrm{~h}$ at $20^{\circ} \mathrm{C}$ with shaking. The wells were then washed six times and DELFIA enhancement solution $(200 \mu \mathrm{l} /$ well $)$ was added to all wells. After incubation for five minutes at $20^{\circ} \mathrm{C}$ with shaking, the time-resolved fluorescence signals for the denatured and native samples were measured using a Victor 2 fluorometer (PerkinElmer).

The value obtained from the denatured sample (D) represents the detection of total $\operatorname{PrP}$ i.e. $\operatorname{PrP}^{\mathrm{C}}+\operatorname{PrP}^{\mathrm{Sc}}$. The value obtained for the native sample $(\mathrm{N})$, without denaturation, represents $\operatorname{PrP}^{\mathrm{C}}$. Therefore, $\mathrm{D}-\mathrm{N}$ is directly proportional to $\mathrm{PrP}^{\mathrm{Sc}}$. In reality, there may be a small increase in the accessibility of the 3F4 epitope in unfolded $\operatorname{PrP}^{C}$ versus native $\operatorname{PrP}^{C}$. Therefore, to be effective, a 
preparative step is necessary to remove the majority of $\operatorname{PrP}^{\mathrm{C}}$ prior to analysis.

\section{Calibration of CDI}

The CDI assay for PrP was calibrated using full-length human recombinant $\operatorname{PrP}$ (recHuPrP, amino acids 23-231, methionine at codon 129) purified as described previously [15]. A range of dilutions from $40 \mu \mathrm{g} / \mathrm{ml}$ to $10 \mu \mathrm{g} / \mathrm{ml}$ of this recHuPrP was prepared using PBS containing $2 \%$ sarkosyl. Twenty-five $\mu \mathrm{l}$ samples of these dilutions were mixed with an equal volume of $8 \mathrm{M} \mathrm{GdnHCl}$ and denatured as described above. These samples were adjusted to $650 \mu \mathrm{l}$, with water containing complete ${ }^{\mathrm{mm}}$ EDTA-free protease inhibitors and analysed as described above. The time resolved fluorescence counts obtained for the recHuPrP dilution series were used to plot a standard curve of counts versus micrograms of $\operatorname{PrP}$. This curve was used to convert the ' $\mathrm{D}$ ' and ' $\mathrm{N}$ ' CDI signals obtained for known volumes of $10 \%$ (wt/vol) brain homogenates into values with units of micrograms of PrP per gram of brain tissue.

\section{Equilibrium unfolding for the analysis of $\mathrm{PrP}^{\mathrm{Sc}}$ stability} Stability analysis of the $\operatorname{PrP}^{\mathrm{Sc}}$ conformer was performed on two cases of GSS with the P102L mutation (one associated with an $\sim 8 \mathrm{kDa} \operatorname{PrP}^{\text {res }}$ and the other associated with the typical three-band type $1 \operatorname{PrP}^{\text {res }}$ following western blot analysis) and on various brain regions from VPSPr case 1 , for which multiple brain regions were available (Table 2). Frontal cortex and cerebellum from a case of sCJD (VV2 subtype) and two cases of GSS were analysed as controls. To concentrate $\operatorname{PrP}^{\mathrm{Sc}}$, the brain tissue homogenates $(100 \mu \mathrm{l})$ were centrifuged $\left(1 \mathrm{~h}\right.$ at $20,000 \mathrm{~g}$ at $\left.4^{\circ} \mathrm{C}\right)$ [16]. The pellets were resuspended in $50 \mu \mathrm{l}$ of $0.1 \% \mathrm{~N}$-lauroylsarcosine/PBS containing complete ${ }^{\mathrm{Tm}}$ EDTA-free protease inhibitors and a range of $\mathrm{GdnHCl}$ concentrations from 0 to $4 \mathrm{M}$ or $6 \mathrm{M}$ and incubated with shaking $(\sim 500 \mathrm{rpm})$ overnight at $20^{\circ} \mathrm{C}$. The samples were adjusted to a final volume of $650 \mu \mathrm{l}$ and then loaded onto MAR-1 coated plates and analysed by DELFIA ${ }^{\mathrm{mm}}$ using Eu-3F4 as described above. The data were normalised to 'fraction of $\operatorname{PrP}^{\mathrm{Sc}}$ unfolded' by adjusting the value obtained without denaturation $(0 \mathrm{M} \mathrm{GdnHCl})$ to zero and the maximum value to 1 . The data were analysed by non-linear regression assuming a sigmoidal relationship between $\mathrm{GdnHCl}$ concentration and the fraction of $\operatorname{PrP}^{\mathrm{Sc}}$ unfolded.

\section{Western blotting}

The western blot method that was used to analyse the multiple brain regions from VPSPr case 1 has been described previously [17]. The protocol used was one specifically designed to detect poorly protease-resistant $\mathrm{PrP}$ that occurs in the form of a $\sim 8 \mathrm{kDa}$ band in cases with variably protease-sensitive prionopathy. For western blot analysis, samples were homogenized to $10 \%(\mathrm{w} / \mathrm{v})$ in trisbuffered saline, $\mathrm{pH} 7.6$, containing $0.5 \%$ Nonidet P40 and $0.5 \%$ sodium deoxycholate and cleared by centrifugation at $400 \mathrm{~g}$ for $5 \mathrm{~min}$. Aliquots of the cleared 10\% brain homogenates were subjected to limited proteolysis with PK at $50 \mu \mathrm{g} / \mathrm{ml}$ for $1 \mathrm{~h}$ at $37^{\circ} \mathrm{C}$ terminated with $1 \mathrm{mM}$ Pefabloc SC (Roche, Burgess Hill, UK). Unless otherwise stated, maximal volumes of $24 \mu \mathrm{l}$ were loaded onto the gel. Polyacrylamide gel electrophoresis and Western blotting was performed using the NuPAGE Novex gel system (Life Technologies, Paisley, UK). The gel electrophoresis time was shortened to retain low molecular mass proteins $[5,8]$. The immunodetection of $\mathrm{PrP}$ was achieved using the monoclonal antibodies 3F4 (epitope 106-112, from Millipore, Watford, UK) at final concentrations of $75 \mathrm{ng} / \mathrm{ml}$ or 94B4 (epitope 187-194, from Central Veterinary Institute of Wageningen UR, Lelystad, The Netherlands) at a concentration of 1:5000 for $1 \mathrm{~h}$. The secondary antibody used was ECL Mouse IgG, HRP-linked whole Ab (GE Healthcare Life Sciences, Amersham, United Kingdom). The detection reagent employed was Amersham ECL Prime western Blotting Detection Reagent (GE Healthcare Life Sciences). The blots were imaged and analysed by densitometry using the ChemiDoc ${ }^{\mathrm{rm}} \mathrm{XRS}+$ System with Image Lab ${ }^{\text {tw }}$ Software (Bio-Rad, Hemel Hempstead, UK).

\section{Protein misfolding cyclic amplification (PMCA)}

PMCA was carried out as described previously [18]. VPSPr cases 2 and 3, both VV at PRNP-codon 129, were selected in which a distinction had been observed in the western blot $\operatorname{PrP}^{\text {res }}$ pattern between the frontal cortex (predominantly $\sim 8 \mathrm{kDa}$ fragment) and the cerebellum (bands of $18-30 \mathrm{kDa}$, in a pattern similar to type $2 \mathrm{~A}$ ). The two VPSPr cases, numbered 2 and 3 in this study, correspond to cases 4 and 3 , respectively, in the retrospective review of UK cases (Table 2) [7]. Brain homogenate was prepared from the frontal cortex $(\mathrm{FC})$ and cerebellum $(\mathrm{Cb})$ of VPSPr cases 2 and 3 for use as seeds. For comparison, PMCA was also carried out on frontal cortex tissue from a case of SCJD (VV2 subtype) and two cases of GSS with the P102L mutation, one associated with $\sim 8 \mathrm{kDa}$ and the other associated with type $1 \mathrm{PrP}^{\text {res }}$. The brain homogenates used as substrates were prepared from either frontal cortex of non-CJD patients, or humanised transgenic mouse brain, with compatible PRNP-codon 129 genotypes (VV in the case of VPSPr and SCJD VV2 subtype) and MM for both cases of GSS). The (seed:substrate) volume ratios were as follows: VPSPr cases (1:4), GSS and sCJD cases (1:9). Low molecular mass heparin $(100 \mu \mathrm{g} / \mathrm{ml})$ was included in all PMCA reactions [19].

\section{Real-time quaking induced conversion (RT-QuIC)}

We used RT-QuIC to examine the seeding activity of VPSPr case 1, versus a sCJD VV2 case and a non-CJD 
case (amyotrophic lateral sclerosis with frontotemporal lobar dementia). The method used for the RT-QuIC in vitro conversion assay was as described previously [15] with some modifications. Full length hamster recombinant PrP (aa 23-231; GenBank accession no. K02234) was exclusively used as a substrate. This was expressed and purified as described previously [15], and provided by Dr Gary Mallinson, NHS Blood and Transplant, Bristol, UK. Brain seeds were prepared by homogenising frozen tissue samples using a Fastprep machine (as described above) in PBS containing $1 \mathrm{mM}$ EDTA, $150 \mathrm{mM} \mathrm{NaCl}$, 0.5\% Triton X-100 and Complete Mini EDTA-free Protease Inhibitor Cocktail (Roche) to give a final tissue concentration of $10 \%(\mathrm{w} / \mathrm{v})$. The amounts of brain homogenate introduced into the RT-QuIC assays were normalized according to the concentration of $\mathrm{PrP}^{\text {res }}$ determined by quantitative analysis of western blots in which brain samples had been run against known amounts of recombinant PrP [15]. Dilutions of the brain homogenates were performed using PBS containing $0.1 \%$ sodium dodecyl sulphate (SDS). The RT-QuIC reactions were a final volume of $100 \mu \mathrm{l}$ and contained recombinant $\mathrm{PrP}$ at a final concentration of $0.1 \mathrm{mg} / \mathrm{ml}$. The reactions were initiated by the addition of $2 \mu \mathrm{l}$ of the appropriately diluted seed. The plates were incubated at $42^{\circ} \mathrm{C}$ and shaken intermittently at 900 r.p.m. (87 sec shaking, $33 \mathrm{~min}$ at rest) using a FLUOstar OMEGA microplate reader (BMG Labtech) in a double orbital configuration. Fluorescence readings were taken at $480 \mathrm{~nm}$ every $15 \mathrm{~min}$ from the bottom of the wells after excitation with 20 flashes per well at $450 \mathrm{~nm}$. Thioflavin-T emission counts (relative fluorescence units) increased to a maximum limit of 260,000 per well.

\section{Sucrose density gradient centrifugation (SDGC)}

SDGC was performed as described previously [12] to separate $\operatorname{PrP}^{\mathrm{Sc}}$ aggregates according to their densities from samples of frontal cortex from VPSPr case 1, and case of sCJD VV2. Frontal cortex from a non-CJD case was separated as a control. Briefly, centrifugation was carried out in an Optima ${ }^{\mathrm{sm}}$ TLX Ultracentrifuge (Beckman Coulter) using an MLS-50 swinging bucket rotor. The sucrose gradient used was set up in a $5 \mathrm{ml}$ ultracentrifuge tube. Each step was $745 \mu \mathrm{l}$ and the dilutions were, from bottom to top, 60, 30, 25, 20, 15 and 10\% sucrose in Tris-buffered saline containing $1 \% \mathrm{~N}$-lauroylsarcosine. Whole brain homogenate $5 \%(\mathrm{w} / \mathrm{v})$ containing $2 \% \mathrm{~N}$-octyl glucopyranoside (NOG) in PBS (1X) was clarified and loaded on top of the sucrose gradient and centrifuged at $4^{\circ} \mathrm{C}$ and 50,000 g for $1 \mathrm{hr}$, all as described in [12]. During centrifugation the sucrose gradient becomes continuous. After centrifugation 11 fractions of $450 \mu \mathrm{l}$ were collected by pipetting from the top of the gradient. Therefore, the density of the fractions increases from 1-11. For western blot analysis, fractions were PK digested (50 $\mu \mathrm{g} / \mathrm{ml} \mathrm{PK}, 1 \mathrm{~h}$ ) and precipitated with nine volumes of methanol overnight at $-80^{\circ} \mathrm{C}$ and pellets were collected by centrifugation (16000 g for $1 \mathrm{hr}$ ). For RT-QuIC analysis, fraction samples were diluted 1:10 with PBS containing $0.1 \%$ SDS.

\section{Results}

D-N values for VPSPr frontal cortex compared with other prion diseases

Figure 2 shows the D-N values of VPSPr frontal cortex brain homogenates (mean of samples from five patients). These values are compared with frontal cortex from patients with sCJD (of the MM1, MM2 and VV2 subtypes), variant CJD, and two cases of GSS (both P102L mutation of PRNP). Cases with a diagnosis other than prion

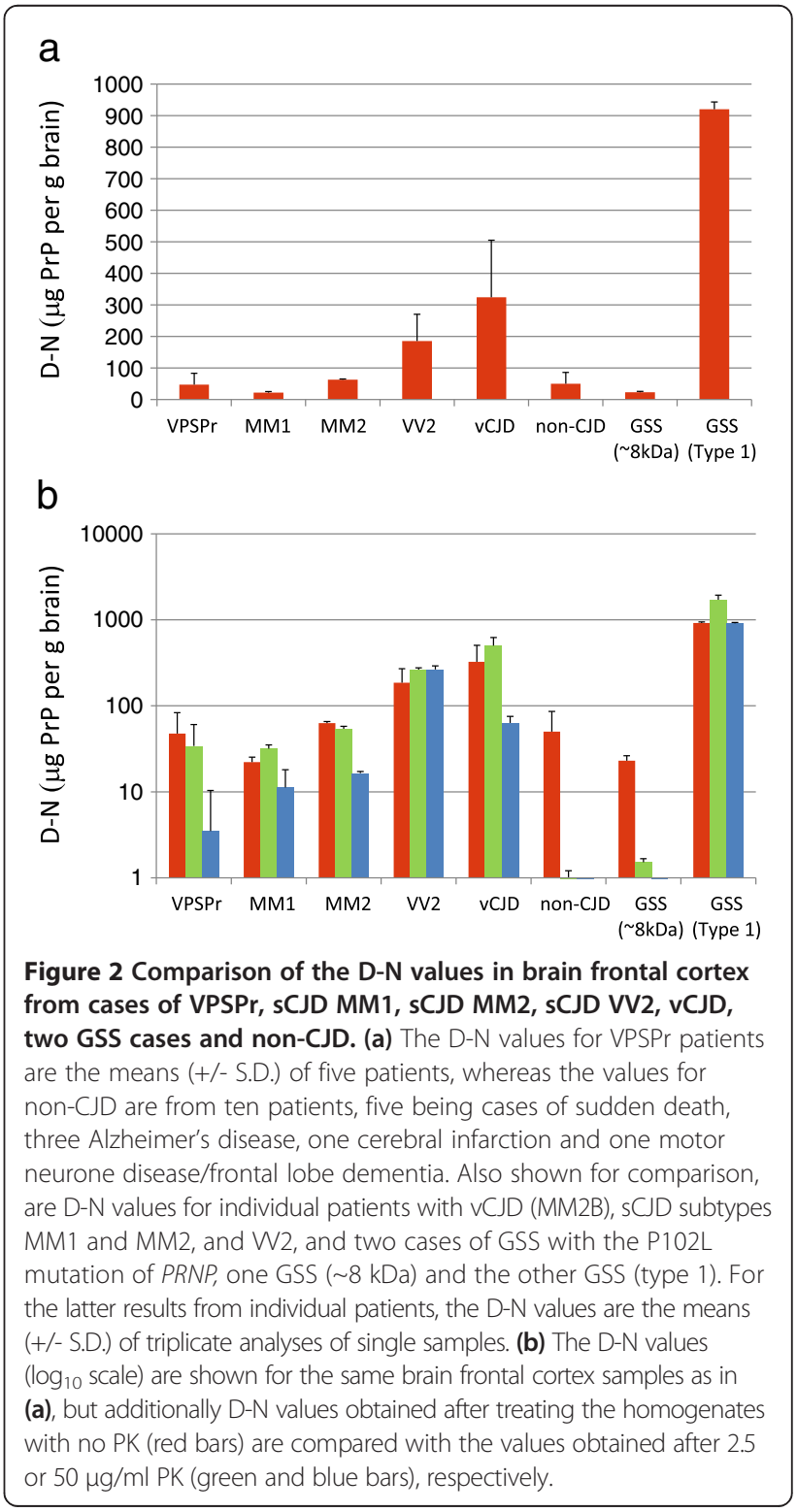


disease (non-CJD) are included as a negative control. This analysis was performed after no treatment (Figure 2a), or treatment with 2.5 or $50 \mu \mathrm{g} / \mathrm{ml}$ PK (Figure $2 \mathrm{~b}$ ). In the absence of PK digestion, CDI is ineffective at discriminating between prion disease and non-prion disease specimens: using the mean D-N value for non-CJD cases plus 3 s.d. as a cut-off value (158 $\mu \mathrm{g} \operatorname{PrP}$ per gram brain) only sCJD VV2 subtype, vCJD and GSS (type $1 \mathrm{PrP}^{\text {res }}$ ) give values above this cut-off.

In contrast, CDI could clearly distinguish between prion disease and non-prion disease specimens after pretreament of the homogenates with $2.5 \mu \mathrm{g} / \mathrm{ml}$ PK (Figure 2b, green bars). After this mild PK treatment, the D-N signals were abolished for non-CJD samples, but high $\mathrm{D}-\mathrm{N}$ values were obtained for VPSPr equivalent to those obtained for sCJD MM1 and SCJD MM2. Using the mean [D-N] (+3 s.d.) for non-CJD samples pretreated with $2.5 \mu \mathrm{g} / \mathrm{ml}$ PK as the new cut-off, samples from all prion diseases apart from GSS $(\sim 8 \mathrm{kDa})$ gave values above this threshold. The high D-N signals from the VPSPr, CJD and GSS specimens following denaturation of samples digested with $2.5 \mu \mathrm{g} / \mathrm{ml} \mathrm{PK}$ indicated the presence of $\mathrm{PrP}^{\mathrm{Sc}}$ that resists mild proteolysis, in contrast to $\mathrm{PrP}^{\mathrm{c}}$ which is abolished. Therefore, low concentration PK treatment allows D-N to distinguish between the prion disease samples (VPSPr, CJD, GSS) and the non-CJD group.

High concentration PK treatment $(50 \mu \mathrm{g} / \mathrm{ml})$ abolishes $\mathrm{D}-\mathrm{N}$ in the GSS case associated with $\sim 8 \mathrm{kDa} \operatorname{PrP}^{\text {res }}$ (Figure 2b, blue bars). However, between 2.5 and $50 \mu \mathrm{g} / \mathrm{ml} \mathrm{PK}, \mathrm{D}-\mathrm{N}$ is maintained in sCJD VV2 subtype and GSS (type $1 \mathrm{PrP}^{\mathrm{res}}$ ), but falls in all other prion diseases, the fall being greatest for VPSPr. We can infer that the decrease in D-N between 2.5 and $50 \mu \mathrm{g} / \mathrm{ml} \mathrm{PK}$ is due to the elimination of poorly protease-resistant forms of $\mathrm{PrP}^{\mathrm{Sc}}$, referred to as senPrP $\mathrm{Pc}^{\mathrm{Sc}}$ (Table 1). Alternatively, rather than eliminating $\operatorname{PrP}^{\mathrm{Sc}}, 50 \mu \mathrm{g} / \mathrm{ml} \mathrm{PK}$ digestion may remove the $\mathrm{C}$-terminal epitope for the capture antibody, rendering $\operatorname{PrP}^{\mathrm{Sc}}$ undetectable by CDI. This would be the case if the digestion product was the $\sim 8 \mathrm{kDa}$ fragment observed on western blots for VPSPr and GSS. It is interesting to note that after $50 \mu \mathrm{g} / \mathrm{ml} \mathrm{PK}$, very high $\mathrm{D}-\mathrm{N}$ signals were detected in the GSS (type 1 $\left.\mathrm{PrP}^{\text {res }}\right)$ case, in contrast with the GSS $\left(\sim 8 \mathrm{kDa} \operatorname{PrP}^{\text {res }}\right)$ case, in which D-N was completely abolished at $50 \mu \mathrm{g} / \mathrm{ml} \mathrm{PK}$ (Figure 2).

\section{D-N values for frontal cortex versus cerebellum in VPSPr cases}

CDI analysis comparing frontal cortex and cerebellum for VPSPr cases 1-4, following digestion with 0, 2.5 and $50 \mu \mathrm{g} / \mathrm{ml} \mathrm{PK}$ is shown in Figure 3. Similar to frontal cortex, positive $\mathrm{D}-\mathrm{N}$ value are obtained for cerebellum following treatment with $2.5 \mu \mathrm{g} / \mathrm{ml} \mathrm{PK}$ (Figure 3, red bars). In the frontal cortex of VPSPr cases 2-4 and in the cerebellum of VPSPr case 1 and 4, the D-N values are severely reduced following treatment with $50 \mu \mathrm{g} / \mathrm{ml} \mathrm{PK}$. For VPSPr cases 2 and 3 the D-N values were considerably greater for cerebellum versus frontal cortex after $50 \mu \mathrm{g} / \mathrm{ml}$ PK (Figure 3) suggesting the presence of protease resistant $\mathrm{PrP}^{\mathrm{Sc}}$ with intact $\mathrm{C}$-termini. In these cases, a marked distinction had been seen in the western blot $\operatorname{PrP}^{\text {res }}$ molecular profile for the frontal cortex $\left(\sim 8 \mathrm{kDa} \operatorname{PrP}^{\mathrm{res}}\right)$ and cerebellum (predominantly triple band pattern resembling type 2A PrP ${ }^{\text {res }}$ ) (Figure 4) [7]. However, in VPSPr case 1, the western blot profile showed the presence of $\sim 19$ and $\sim 23 \mathrm{kDa}$ bands in addition to the $\sim 8 \mathrm{kDa}$ band in the frontal cortex (Figure 5), and in agreement with this, CDI analysis showed the preservation of the D-N signal in frontal cortex after treatment with $50 \mu \mathrm{g} / \mathrm{ml}$ PK.

\section{PMCA of VPSPr PrP ${ }^{\mathrm{Sc}}$ from frontal cortex and cerebellum}

VPSPr cases 2 and 3 described above were used to investigate the relative potential for $\mathrm{PrP}^{\mathrm{Sc}}$ from the frontal cortex or the cerebellum to seed the conversion of $\operatorname{PrP}^{C}$ in a PMCA reaction. These cases were selected for this test because of the extreme differences between frontal cortex and cerebellum seen in the western blot $\mathrm{PrP}^{\mathrm{res}}$ pattern and the D-N values after treatment with $50 \mu \mathrm{g} / \mathrm{ml}$ PK (Figure 3). No increase in the abundance of the $\sim 8 \mathrm{kDa}$ $\mathrm{PrP}^{\text {res }}$ in the frontal cortex was observed after PMCA using either non-CJD human brain or humanised transgenic brain substrate (Figure 4). However, the $\sim 19$ and $\sim 23 \mathrm{kDa}$ bands in the VPSPr cerebellum that co-migrate with middle and lower bands of the type $2 \mathrm{~A}$ in SCJD (Figure 1B) were amplified by PMCA using both substrates. Amplification was apparent as the appearance of a band at $\sim 30 \mathrm{kDa}$ and an increase in signal for the $\sim 19$ and $\sim 23 \mathrm{kDa}$ bands. The mean increase in signal (VPSPr cases 2 and 3) for the latter two bands was $\sim 2.6$ - and 1.5-fold, using human and mouse brain substrates, respectively. A $\sim 30 \mathrm{kDa}$ band, that may correspond to diglycosylated $\mathrm{PrP}^{\mathrm{res}}$, also appears when VPSPr frontal cortex samples are amplified by PMCA (Figure 4). The replicative properties of $\mathrm{PrP}^{\mathrm{Sc}}$ from cases of GSS associated with either type 1 or $\sim 8 \mathrm{kDa} \operatorname{PrP}^{\text {res }}$ were also investigated by PMCA. Densitometric analysis indicated a $\sim 1.5$ fold level of amplification, using either human or mouse brain substrate for GSS with type 1 $\operatorname{PrP}^{\text {res }}$ in contrast to a lack of amplification for GSS with an $\sim 8 \mathrm{kDa} \mathrm{PrP}^{\mathrm{res}}$, using human and transgenic mouse brain substrates (Figure 4). In contrast, both the human brain and humanised transgenic mouse brain substrates showed robust amplification when seeded with a SCJD VV2 subtype sample (Figure 4).

\section{Neuropathological correlate}

An interesting question is whether the biochemical and seeding potential differences observed between VPSPr 


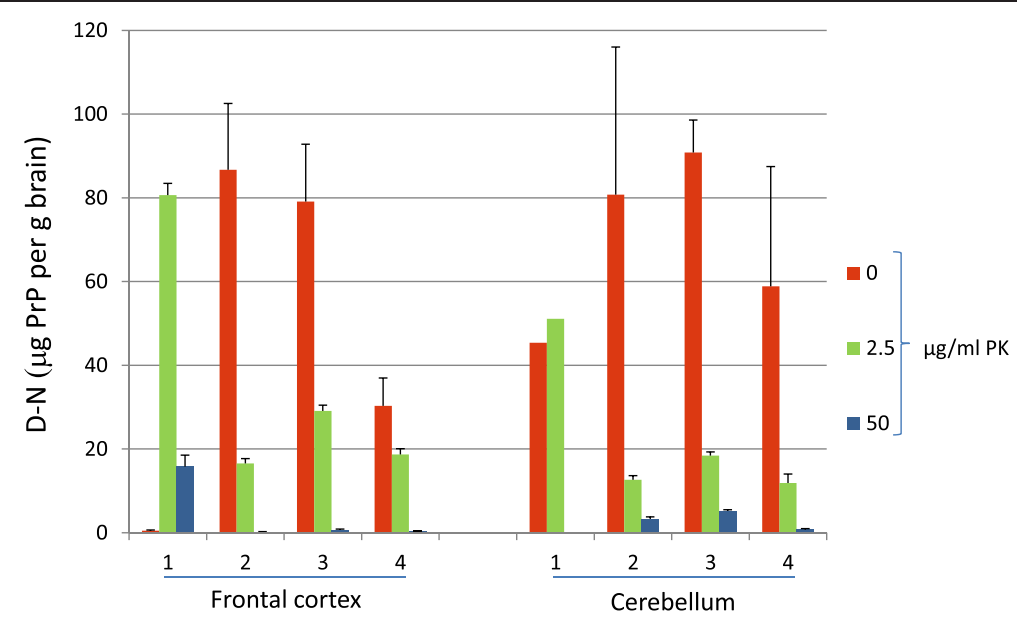

Figure 3 Comparison of VPSPr frontal cortex and cerebellum by CDI. CDI analysis of samples of frontal cortex or cerebellar cortex homogenate from VPSPr cases 1-4 following treatment with 0 (red bars), 2.5 (green bars) or $50 \mu \mathrm{g} / \mathrm{ml}$ PK (blue bars) for $1 \mathrm{~h}$. The error bars are S.D. for triplicate analyses of single samples.

frontal cortex and cerebellum are reflected in regional neuropathology. We were unable to see a clear correlation between the detection of cerebellar $\sim 19$ and $23 \mathrm{kDa}$ PrP $\mathrm{P}^{\text {res }}$ by western blot, (high is cases 2 and 3 ) and the number of cerebellar microplaques between cases (high in cases 2 and 4) (Table 2).

\section{Regional variation in a VPSPr case with extensive available tissue Western blot analysis}

Unlike the other VPSPr cases identified by surveillance in the UK, multiple brain regions were available for analysis from VPSPr case 1 (Table 2). Eleven anatomical regions

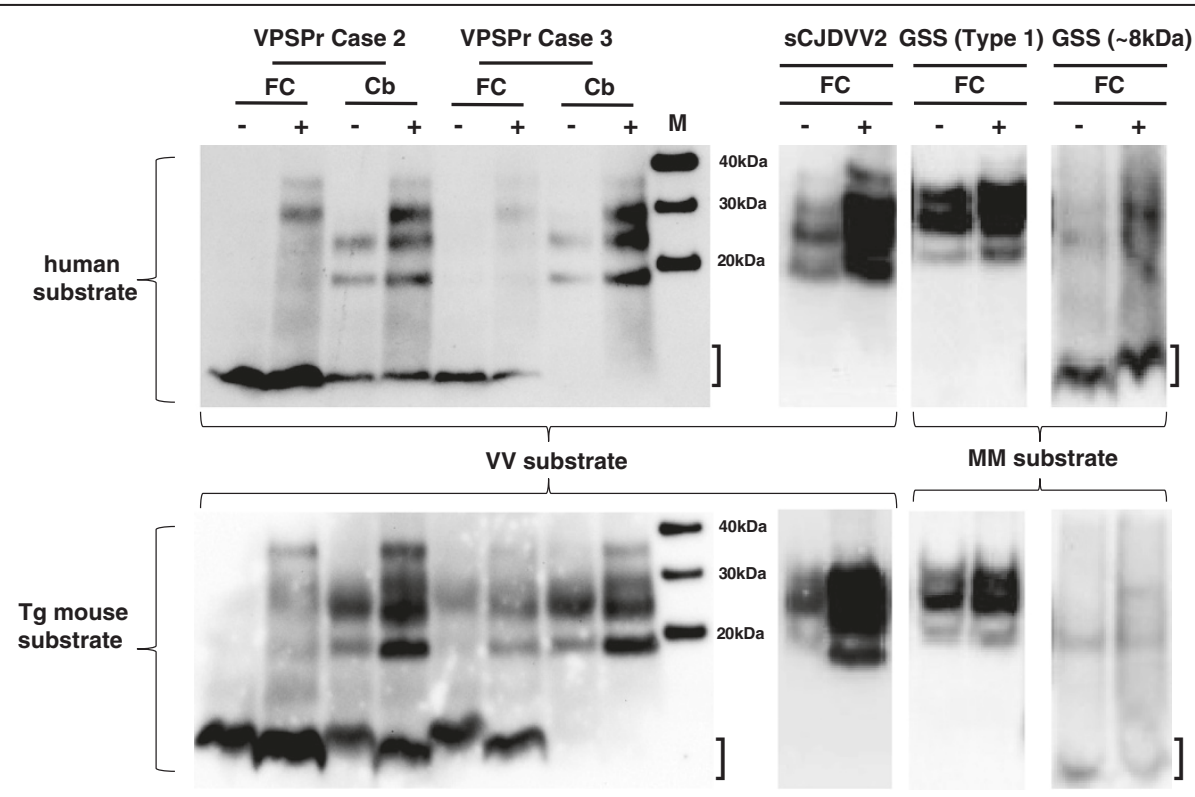

Figure 4 PMCA of VPSPr, GSS and SCJD PrP ${ }^{\text {Sc }}$. Brain homogenate prepared from the frontal cortex (FC) and cerebellum (Cb) of VPSPr cases 2 and 3, and frontal cortex from two cases of GSS (associated with $\sim 8 \mathrm{kDa}$ and type 1 PrP ${ }^{\text {res }}$, respectively) and a case of sCJD W2 were used to seed single-round PMCA reactions. The brain homogenates used as substrates are as indicated in the figure, and were either non-CJD human post mortem brain frontal cortex tissue (upper panel) or humanised transgenic mouse brain expressing human PRNP (lower panel). Substrates with compatible PRNP-codon 129 genotypes were used (V in the case of VPSPr and SCJD W2, and MM for both cases of GSS). The (seed: substrate) volume ratios were as follows: VPSPr cases (1:4), GSS and sCJD cases (1:9). Samples were amplified by PMCA (+) or kept frozen (-). The region of the $\sim 8 \mathrm{kDa}$ PrPres band is indicated with a bracket. Separate immunoblots have been aligned to the molecular mass markers shown in lane $\mathrm{M}$ 


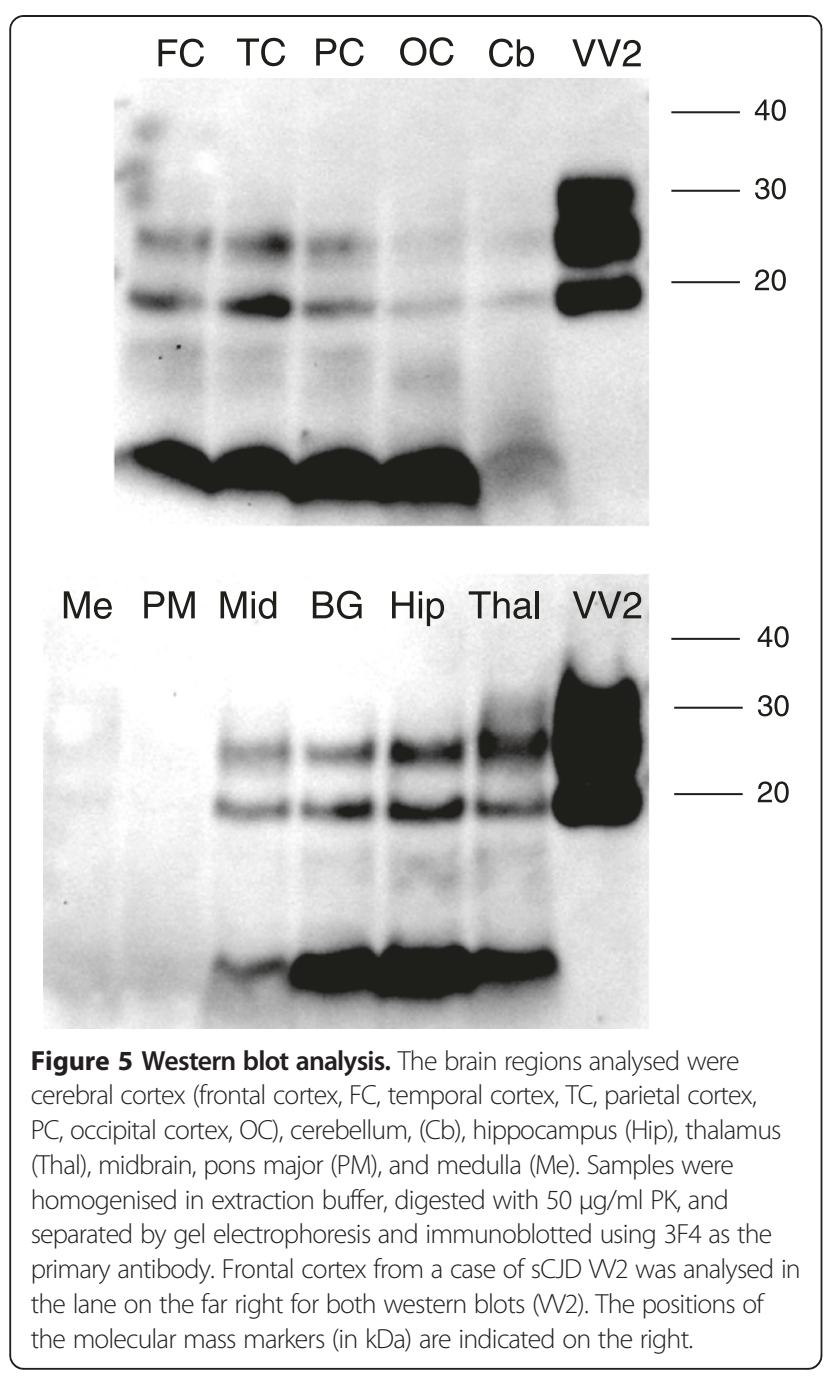

from the brain of case 1 were analysed. Samples were homogenised and prepared for conventional western blot analysis. $\operatorname{PrP}^{\mathrm{res}}$ was widely distributed throughout cortical and subcortical regions with regional variation in the relative levels of the $\sim 8 \mathrm{kDa} \mathrm{PrP}^{\mathrm{res}}$ and two bands that appeared to co-migrate with the unglycosylated and mono-glycosylated $\operatorname{PrP}^{\text {res }}$ bands of the sCJD VV2 subtype at $\sim 23$ and $\sim 19 \mathrm{kDa}$ (Figure 5). The band corresponding to diglycosylated $\operatorname{PrP}$ was not visible. The brain regions with the highest overall signal intensities were hippocampus $>$ occipital cortex $>$ parietal cortex, whereas $\operatorname{PrP}^{\text {res }}$ was largely absent from the medulla and pons. The $\sim 8 \mathrm{kDa}$ band was predominant in most regions, but its predominance was highest for the occipital cortex and lowest for the midbrain and thalamus (Figure 5).

\section{Comparison of D-N values from multiple regions from a single case of VPSPr}

Samples from VPSPr case 1 were taken from exactly the same anatomical regions as those analysed by western blotting and analysed by $\mathrm{CDI}$, for both $\mathrm{PrP}^{\mathrm{Sc}}$ stability and relative levels of $\operatorname{PrP}^{\mathrm{Sc}}$, as inferred from $\mathrm{D}-\mathrm{N}$. These samples were compared with available samples from the two GSS cases used above. Samples were homogenised and underwent digestion with $0,1,2.5,10$ or $50 \mu \mathrm{g} / \mathrm{ml}$ $\mathrm{PK} . \mathrm{PrP}^{\mathrm{Sc}}$ was detectable in all VPSPr brain regions apart from medulla using CDI analysis (Figure 6), which is in partial agreement with the western blot analysis for $\operatorname{PrP}^{\text {res }}$. The highest $\mathrm{D}-\mathrm{N}$ values were detected in the parietal cortex and basal ganglia, and also the occipital cortex and midbrain. The lowest D-N levels were detected in the thalamus and medulla. Negligible D-N signals were obtained for frontal cortex from a case of amyotrophic lateral sclerosis with frontotemporal lobar dementia (ALS-FTLD) used as a control (data not shown).

To be detected by CDI the protease resistant $\operatorname{PrP}^{\mathrm{Sc}}$ must contain the epitope to 3F4 and the C-terminal epitope to MAR-1 making the $\sim 8 \mathrm{kDa} \operatorname{PrP}^{\mathrm{res}}$ fragment, characteristic of VPSPr and GSS cases, undetectable by CDI (Figure 1a). In GSS (type $1 \mathrm{PrP}^{\mathrm{res}}$ ) and sCJD VV2 there is CDI detectable material even at the highest $50 \mu \mathrm{g} / \mathrm{ml} \mathrm{PK}$ concentration. However, in GSS $\left(\sim 8 \mathrm{kDa} P r P^{\text {res }}\right)$ little or none survives $2.5 \mu \mathrm{g} / \mathrm{ml}$ PK. Regional analysis of VPSPr case 1 shows them to be intermediate in profile: after treatment with $50 \mu \mathrm{g} / \mathrm{ml} \mathrm{PK}, \mathrm{PrP}^{\mathrm{Sc}}$ remained detectable in the parietal cortex in a manner that resembles GSS (type $1 \mathrm{PrP}^{\mathrm{res}}$ ) and sCJD VV2 subtype (Figure 6), and after $10 \mu \mathrm{g} / \mathrm{ml} \mathrm{PK}, \operatorname{PrP}^{\mathrm{Sc}}$ was detected in midbrain, basal ganglia and hippocampus. However, a high PK concentration largely eliminated CDI-detectable $\mathrm{PrP}^{\mathrm{Sc}}$ from the other regions, and this PK sensitivity therefore resembles GSS $\left(\sim 8 \mathrm{kDa} \operatorname{PrP}^{\text {res }}\right)$.

\section{Comparison of $\mathrm{PrP}^{\mathrm{Sc}}$ stability in multiple regions from a single case of VPSPr}

$\mathrm{PrP}^{\mathrm{Sc}}$ is insoluble in detergents such as $N$-lauroylsarcosine and can be concentrated by centrifugation. We confirm this here by showing that $\operatorname{PrP}^{\mathrm{Sc}}$ (inferred from positive $\mathrm{D}-\mathrm{N}$ values) is pelleted from VPSPr frontal cortex homogenate, but is absent from the centrifugal pellet obtained from non-CJD brain homogenate (Additional file 1: Figure S2).

The insoluble pellet can then be used to measure the stability of VPSPr PrP ${ }^{\mathrm{Sc}}$ in the absence of PK. Samples were centrifugally concentrated from $100 \mu \mathrm{l}$ aliquots of homogenate, prior to denaturation with increasing concentrations of $\mathrm{GdnHCl}$. By increasing the signal for $\operatorname{PrP}^{\mathrm{Sc}}$ and removing detergent soluble PrP, centrifugal concentration enabled the determination of $\mathrm{PrP}^{\mathrm{Sc}}$ stability in regions such as medulla in which $\mathrm{PrP}^{\mathrm{Sc}}$ had been close to, or below, the limit of detection in the previous CDI analysis (Figure 6). The equilibrium denaturation curves for the analysis of brain regions from VPSPr case 1 are shown in Additional file 1: Figure S3 along with the $[\mathrm{GdnHCl}]^{1 / 2}$ values and the $95 \%$ confidence intervals $(\mathrm{CI})$. 


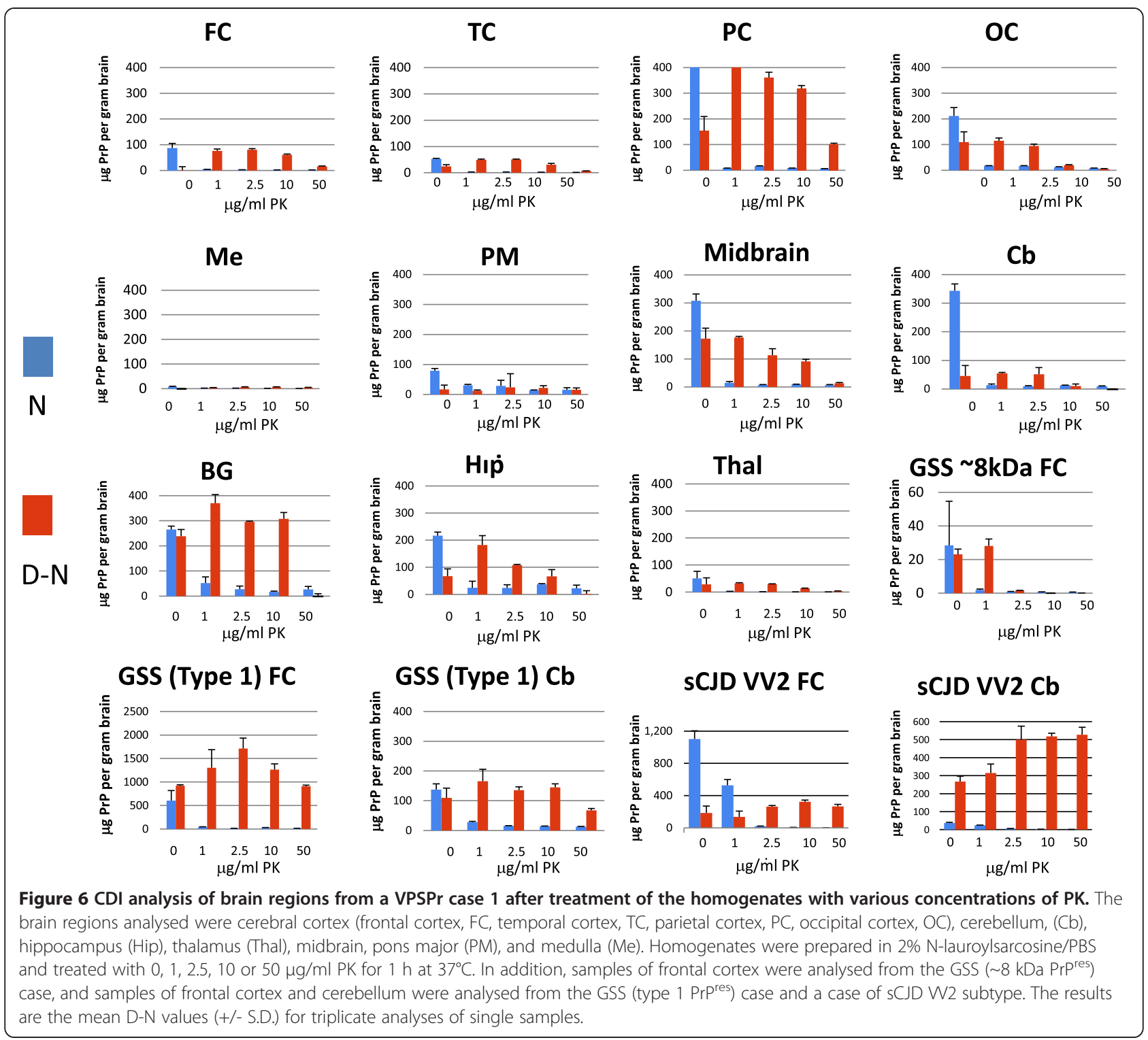

The $[\mathrm{GdnHCl}]^{1 / 2}$ values and $\mathrm{CI}$ values are also summarised in Table 3 and Figure 7. Although $\operatorname{PrP}^{\mathrm{Sc}}$ stability analysis in VPSPr was restricted to a single case (case 1) where multiple regions were available, extensive analysis of another human prion disease subtype, vCJD, gives an indication of the precision of this method. For example, analysis of vCJD frontal cortex gave a mean [GdnHCl] $]^{1 / 2}$ value of 1.678 (S.D., \pm 0.175 ) for three separate vCJD cases [12]. All regions of this VPSPr case (and GSS and sCJD positive controls) show a simple sigmoidal transition when unfolded by increasing guanidine concentrations. The regional $[\mathrm{GdnHCl}]^{1 / 2}$ values for this VPSPr case varied dramatically, being lowest in occipital cortex $\left([\mathrm{GdnHCl}]^{1 / 2}=1.63\right)$ and highest in the cerebellum $\left([\mathrm{GdnHCl}]^{1 / 2}=3.52\right)$ (Table 3). Analysis of multiple adjacent samples from frontal cortex and cerebellum from VPSPr case 1 showed that the difference in the $[\mathrm{GdnHCl}]^{1 / 2}$ values for these regions was statistically significant (Table 4). In the GSS (type $1 \mathrm{PrP}^{\text {res }}$ ) case, no distinction was seen between the stabilities of frontal cortex and cerebellum $\operatorname{PrP}^{\mathrm{Sc}}$, although in both cases it was high compared with $\operatorname{PrP}^{\mathrm{Sc}}$ in the GSS $\sim 8 \mathrm{kDa}$ $\mathrm{PrP}^{\text {res }}$ frontal cortex (Table 3). In sCJD VV2 subtype frontal cortex, $\mathrm{PrP}^{\mathrm{Sc}}$ was more stable than cerebellar $\operatorname{PrP}^{\mathrm{Sc}}$, the latter being in the same range as VPSPr frontal cortex (Table 3). This suggests that the difference observed in VPSPr case 1 is not an effect of cerebellum per se, but of the actual stability of the $\operatorname{PrP}^{\mathrm{Sc}}$ that is present in different neuroanatomical regions of this VPSPr brain. 
Table 3 Summary of [GdnHCI] $1 / 2$ values for brain regions from the VPSPr case and the GSS cases

\begin{tabular}{lll}
\hline Brain region & $\begin{array}{l}\text { [GdnHCL]1/2 } \\
\text { value }\end{array}$ & $\begin{array}{l}\text { 95\% confidence interval } \\
\text { for the curve fit. }\end{array}$ \\
\hline VPSPr frontal cortex & 2.21 & 0.11 \\
VPSPr temporal cortex & 2.01 & 0.42 \\
VPSPr parietal cortex & 2.07 & 0.39 \\
VPSPr occipital cortex & 1.63 & 0.21 \\
VPSPr Me & 2.87 & 0.35 \\
VPSPr pons & 2.92 & 0.23 \\
VPSPr Midbrain & 1.8 & 0.61 \\
VPSPr cerebellum & 3.52 & 0.11 \\
VPSPr basal ganglia & 2.08 & 0.21 \\
VPSPr Hip & 2.2 & 0.26 \\
VPSPr Thal & 2.32 & 0.31 \\
sCJD W2 FC & 2.44 & 0.22 \\
SCJD W2 Cb & 1.94 & 0.1 \\
GSS frontal cortex & 2.57 & 0.06 \\
(type 1 PrPres case) & & \\
GSS cerebellum & 2.64 & 0.06 \\
(type 1 PrPres case) & & \\
GSS frontal cortex & 1.68 & 0.36 \\
( 8 kDa frag. case) & & \\
\hline The [GdnHCl]1/2 values shown here were obtained from the curve fits shown in \\
Additional file 1: Figure S3. The data used to obtain the curve fits were from \\
single samples, or in the case of VPSP FC, Cb and PC, data merged from the \\
analyses of 4, 3 or 2 samples, respectively.
\end{tabular}

\section{Samples from VPSPr contain seeding activity in RT-QuIC}

We investigated whether VPSPr could also seed conversion of recombinant PrP in RT-QuIC. After normalising for the concentration of $\operatorname{PrP}^{\text {res }}$ (as determined by quantitative western blot), dilutions of either VPSPr case 1 or sCJD VV2 brain frontal cortex homogenate were used to seed the RT-QuIC reactions. Both VPSPr and sCJD VV2 brain homogenates seeded conversion. The efficiency of seeding on the basis of the lag time to a rise in ThT fluorescence over 60 hours, was lower for VPSPr per unit $\operatorname{PrP}^{\text {res }}$ compared with sCJD VV2 (Figure 8). No conversion was observed for reactions seeded with equivalent dilutions of non-CJD brain homogenate or unseeded reactions.

\section{RT-QuIC seeding activity of VPSPr and VV2 SCJD after} sucrose density gradient separation (SDGC)

SDGC was used to separate $\operatorname{PrP}^{\mathrm{Sc}}$ aggregates from VPSPr and SCJD VV2 subtype brain according to the relative densities of aggregates. Figure 9a shows the direct western blot analysis of homogenate from a sample of frontal cortex from VPSPr case 1 that was adjacent to the sample used in the SDGC analysis. Western blot analysis of the SDGC fractions indicated that SCJD VV2 subtype brain $\mathrm{PrP}^{\mathrm{Sc}}$ is predominantly in lower (heavier or more dense)

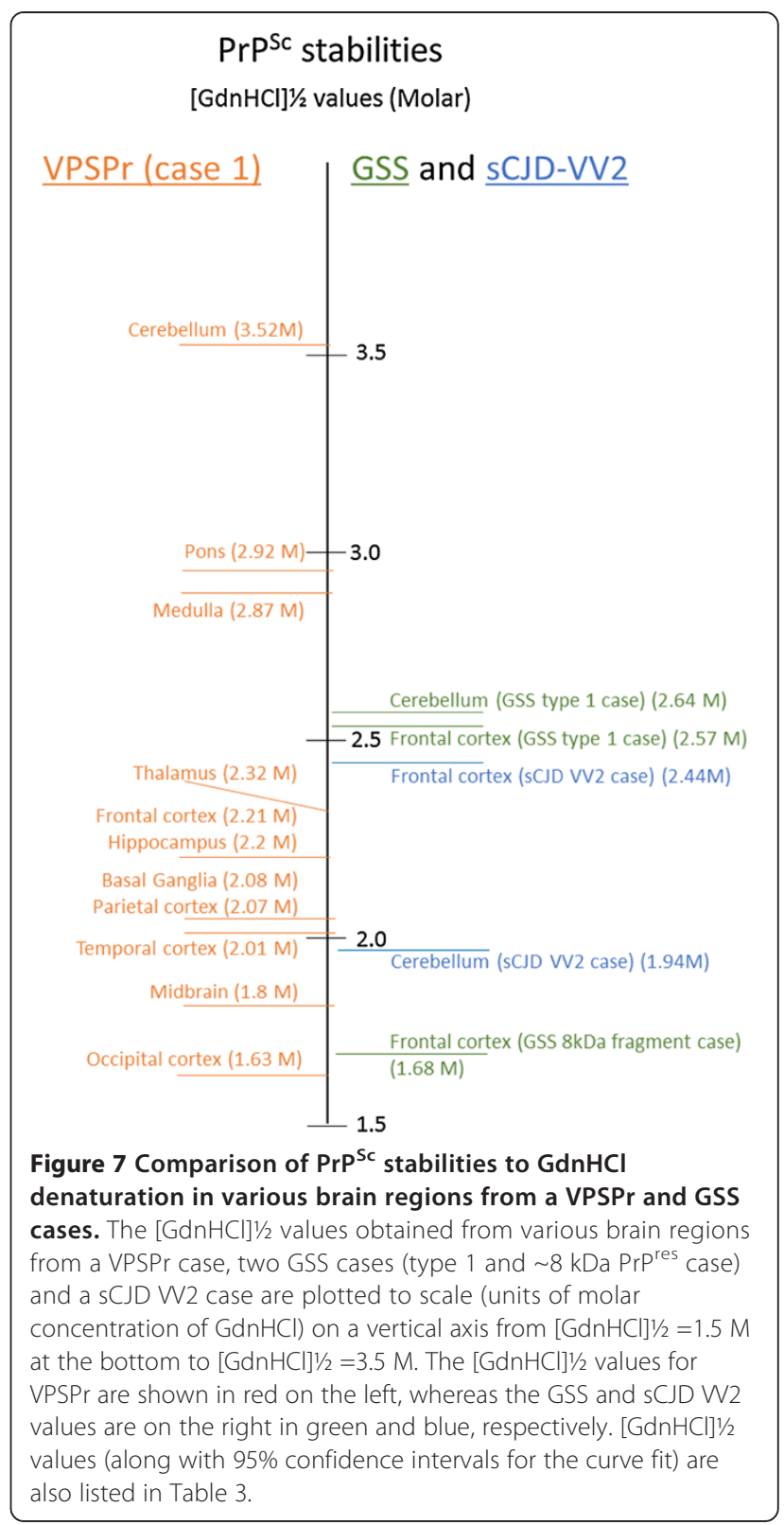

fractions as judged by $\mathrm{PK}$ digestion and $\mathrm{PrP}^{\mathrm{res}}$ detection by western blot (Figure 9b, upper panel). However, VPSPr $\mathrm{PrP}^{\mathrm{Sc}}$ separates into a $\sim 19$ and $\sim 23 \mathrm{kDa}$ PrP ${ }^{\text {res }}$ form found in the lower fractions and an $\sim 8 \mathrm{kDa} \mathrm{PrP}^{\text {res }}$ form in the upper (lighter or less dense) fractions as judged by PK digestion and western blot (Figure 9b, lower panel). No detectable $\operatorname{PrP}^{\mathrm{Sc}}$ was found in the bottom (most dense) fraction. Densitometry of the $\sim 8 \mathrm{kDa}$ and $19 / 23 \mathrm{kDa}$ $\mathrm{PrP}^{\text {res }}$ components before (38\%:62\%) and after (31\%:69\%) centrifugation suggests that the balance of these two distinct $\operatorname{PrP}^{\text {res }}$ subpopulations is largely unaffected by SDGC.

The fractions obtained following SDGC separation of samples of VPSPr, sCJD VV2 and non-CJD brain homogenate were investigated for their seeding potential, using 
Table $4 \operatorname{PrP}^{\mathrm{Sc}}$ stability analysis of multiple samples from frontal cortex and cerebellum from VPSPr case 1

\begin{tabular}{llll}
\hline & FC $(\mathbf{n}=\mathbf{4})$ & $\mathbf{C b}(\mathbf{n}=\mathbf{3})$ & T-Test $(\mathrm{FC}$ vs $\mathbf{C b})$ \\
\hline$[\mathrm{GdnHCl}] 1 / 2 \pm$ S.E. & $2.28 \pm 0.08$ & $3.60 \pm 0.14$ & $P=0.003$ \\
\hline
\end{tabular}

The data shown are the mean $[\mathrm{GdnHCl}] 1 / 2$ values ( \pm standard error) for separate curve fits obtained from separate samples of frontal cortex $(\mathrm{FC})$ and cerebellum (Cb) from VPSPr case 1.

the RT-QuIC assay. Using ThT fluorescence at 40 hours as a measure, seeding potential was associated with a broad range of densities for both the SCJD VV2 subtype and VPSPr (Figure 9b). In the case of sCJD VV2, all fractions seeded RT-QuIC. For VPSPr case 1 seeding activity was markedly reduced in the uppermost fractions ( 1 and 2) in which the $\sim 8 \mathrm{kDa} \operatorname{PrP}^{\text {res }}$ was found.

\section{Discussion}

\section{Biochemical and functional aspects of the $\mathrm{PrP}^{\mathrm{Sc}}$ types present in VPSPr}

These results firstly show that VPSPr $\operatorname{PrP}^{\mathrm{Sc}}$ is detectable by CDI, but only after mild treatment with proteinase K. Therefore VPSPr, in common with all other human prion diseases, is associated with a misfolded form of PrP in which the 3F4 epitope (amino acids 106-112) is concealed. After treatment with $2.5 \mu \mathrm{g} / \mathrm{ml}$ $\mathrm{PK}$, the D-N values for VPSPr were comparable to those for sCJD, MM1 and MM2, but less than those obtained for sCJD VV2 subtype, vCJD and GSS (type 1 PrPres).
It is interesting to note that in the case of $\mathrm{sCJD} \mathrm{VV} 2$ and GSS (type $1 \mathrm{PrP}^{\mathrm{res}}$ ) high $\mathrm{D}-\mathrm{N}$ signals remained regardless of the concentration of $\mathrm{PK}$ used. The particularly high values obtained for the sCJD VV2 subtype are in agreement Saverioni et al who showed that VV2 has the highest PK-resistance among SCJD types and that VPSPr is much less resistant [20]. However, in our study we have shown that in a case of GSS (with $\sim 8 \mathrm{kDa} P r \mathrm{P}^{\text {res}}$ ) any CDI detectable $\operatorname{PrP}^{\text {res }}$ was eliminated with even mild PK treatment. Therefore, VPSPr appears to be intermediate between these two extremes: Although a considerable proportion of VPSPr PrP ${ }^{\mathrm{Sc}}$ was sensitive to proteolysis with high $\mathrm{PK}$, some $\mathrm{PrP}^{\mathrm{Sc}}$ remained.

In two VPSPr cases, the $\mathrm{PrP}^{\mathrm{Sc}}$ detectable after high $\mathrm{PK}$ treatment was considerably greater for cerebellum than frontal cortex. Western blot analysis of these cases had previously shown that frontal cortex $\mathrm{PrP}^{\mathrm{res}}$ was predominantly $\sim 8 \mathrm{kDa}$, whereas cerebellum $\mathrm{PrP}^{\text {res }}$ had a triple band pattern consistent with type $2 \mathrm{~A} \mathrm{PrP}^{\text {res }}$ [7]. Interestingly, in VPSPr case 1, bands at $\sim 19$ and $\sim 23 \mathrm{kDa}$, co-migrating with the lower and middle bands of type 2A PrP ${ }^{\text {res }}$ were observed in frontal cortex by western blotting. These bands were detectable using an antibody directed against the C-terminus of PrP. CDI analysis of frontal cortex from VPSPr case 1 following digestion with $50 \mu \mathrm{g} / \mathrm{ml}$ PK indicated the presence of resistant $\mathrm{PrP}^{\mathrm{Sc}}$ with an intact $\mathrm{C}$-terminus. Therefore, CDI in combination with stringent PK digestion is a sensitive method for mapping PrP ${ }^{\text {res }}$ in VPSPr that has a

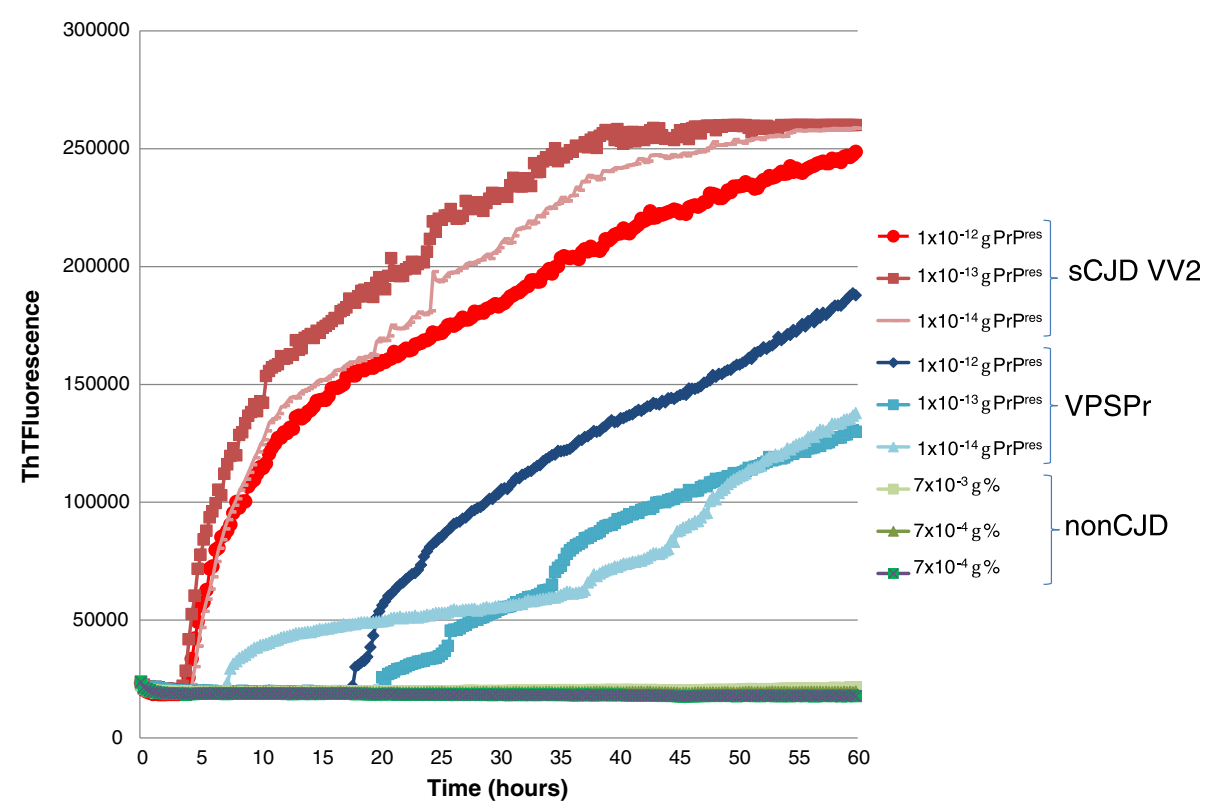

Figure 8 VPSPr PrP ${ }^{S c}$ can seed conversion in RT-QulC. The reactions were seeded with three 10-fold dilutions of VPSPr or SCJD W2 brain amount, normalised according the titre of $\operatorname{PrP}^{\text {res }}$ (units shown are grams PrPres per $100 \mu \mathrm{l}$ reaction volume). As a control, equivalent dilutions of non-CJD brain homogenate (shown as\% [w/v]) were used to seed parallel reactions. Mean ThT fluorescence values (relative fluorescence units) for the quadruplicate reactions were plotted against time (hours). 
a

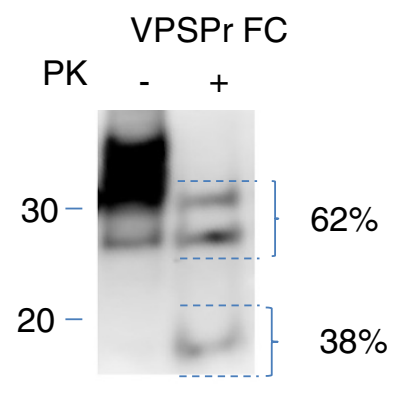

b

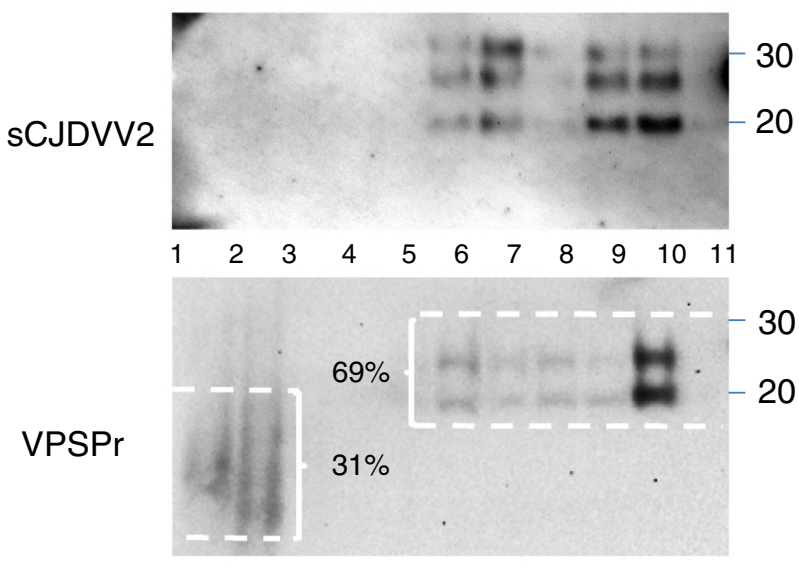

C

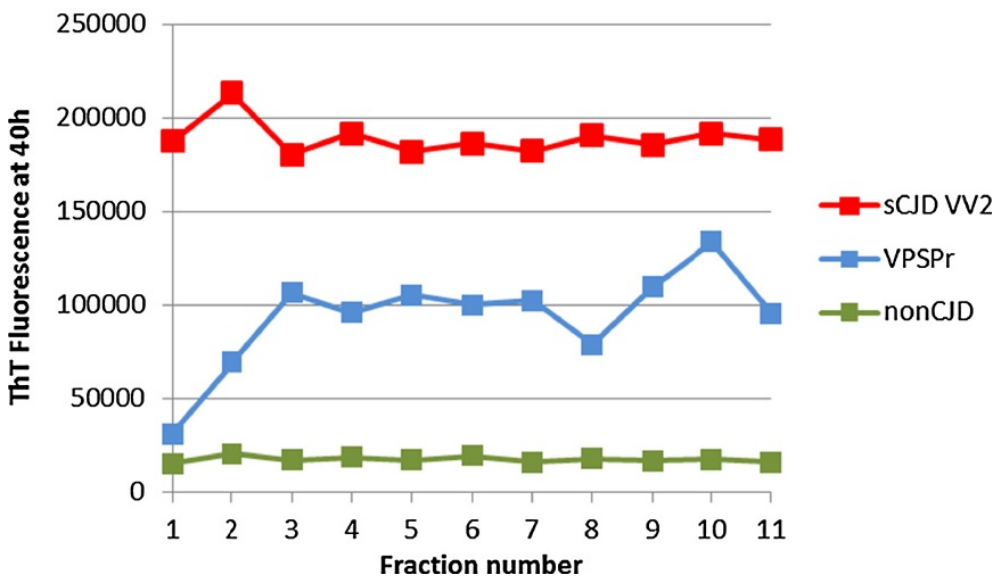

Figure 9 RT-QuIC seeding activity of VPSPr and VV2 sCJD after sucrose density gradient separation. (a) An adjacent sample from VPSPr frontal cortex to the one analysed below [in (b)] was homogenised to $10 \% \mathrm{~W} / \mathrm{V}$ in extraction buffer and analysed by immunoblotting using $3 \mathrm{~F} 4$ as the primary anti-PrP monoclonal antibody either without prior PK digestion (15 $\mu$ l) or following digestion with $50 \mu \mathrm{g} / \mathrm{ml}$ PK and centrifugal concentration (from $100 \mu \mathrm{l}$ ). The densitometric analysis of the $\sim 19$ and $\sim 23 \mathrm{kDa}$ bands versus the $\sim 8 \mathrm{kDa}$ band in this sample is superimposed on the figure. (b) Samples of SDGC fractions from VPSPr case $1(200 \mu \mathrm{l})$ and SCJD W2 $(100 \mu \mathrm{l})$ were PK treated $(50 \mu \mathrm{g} / \mathrm{ml}, 1 \mathrm{~h})$ precipitated overnight with nine volumes of methanol, and analysed for PrPres by western blotting. The positions of molecular mass markers (in kDa) are indicated on the right. The collective densitometric analysis of the $\sim 19$ and $\sim 23 \mathrm{kDa}$ bands versus the $\sim 8 \mathrm{kDa}$ bands in the SDGC-separated sample is superimposed on the figure. (c) VPSPr (case 1), sCJD W2 and non-CJD brain homogenate were separated by sucrose density gradient centrifugation (SDGC). The gradient used was 10-60\% sucrose and after centrifugation eleven fractions of increasing density were successively taken from the top of the tube (\#1 = lowest density, \#11 highest density). Duplicate RT-QulC reactions were seeded with $2 \mu \mathrm{l}$ samples of 1:10 dilutions of the fractions. The ThT relative fluorescence values plotted are the means of the duplicate reactions at 40 hours. 
protease-resistant $\mathrm{C}$-terminus, and in that respect resembles that found in SCJD.

\section{In vitro seeding activity and aggregate size}

We are the first to show that brain homogenate from VPSPr can seed the conversion of $\operatorname{PrP}^{\mathrm{C}}$ to $\operatorname{PrP}^{\mathrm{Sc}}$ in a PMCA reaction. When the above mentioned two VPSPr cases, with extreme differences between frontal cortex and cerebellum $\mathrm{PrP}^{\mathrm{res}}$ patterns, were used to seed PMCA reactions, only the $\sim 19$ and $\sim 23 \mathrm{kDa}$ bands present in the cerebellum were amplified with the additional appearance of a band at $\sim 30 \mathrm{kDa}$. Our results indicate cerebellum and frontal cortex $\operatorname{PrP}^{\mathrm{Sc}}$ have different seeding activities, with the amplification products of cerebellum resembling the triple-band pattern of CJD. These results mirrored the results obtained for GSS $(\sim 8 \mathrm{kDa}$ $\mathrm{PrP}^{\mathrm{res}}$ ) versus GSS (type $1 \mathrm{PrP}^{\mathrm{res}}$ ), in which only the latter seeded conversion in PMCA to a low but measurable extent. The different PMCA results obtained for the two anatomical brain regions in VPSPr and the subtypes of GSS suggests that different $\operatorname{PrP}^{\mathrm{Sc}}$ isoforms may give rise to the $\sim 8 \mathrm{kDa}$ band and the type 1 or $2 \mathrm{~A}$ $\mathrm{PrP}^{\mathrm{res}}$ profiles observed by Western blotting, and that these $\mathrm{PrP}^{\mathrm{Sc}}$ isoforms may have different replicative properties. An interesting question is whether the biochemical and seeding potential differences observed between VPSPr frontal cortex and cerebellum reflect neuropathological observations. We were unable to demonstrate a correlation between the detection of $\sim 19$ and $\sim 23 \mathrm{kDa} \operatorname{PrP}^{\text {res }}$ and the presence of cerebellar microplaques between cases. Although our results suggest the co-existence of different $\operatorname{PrP}^{\mathrm{Sc}}$ conformers in separate anatomical regions of VPSPr brains, we are unable to state whether they correspond to separate prion strains. To answer this, it would be necessary to demonstrate the transmission of different agent strains to experimental animals inoculated with samples from separate regions of VPSPr brains.

Both VPSPr and a form of familial CJD associated with the V180I-129 M haplotype (fCJD-V180I), shared a similar PrP ${ }^{\text {res }}$ electrophoretic profile on western blots with a low molecular mass band at $\sim 8 \mathrm{kDa}[10]$ and both lacked diglycosylated PrP and the N181 monoglycoform. Xiao et al. have suggested that VPSPr and fCJD-V180I share a pathway for the propagation of $\mathrm{PrP}^{\mathrm{Sc}}$ in which the conversion of diglycosylated $\operatorname{PrP}^{\mathrm{C}}$ and one of the two possible forms of monoglycosylated $\operatorname{PrP}^{C}$ (mono 181) to $\operatorname{PrP}^{\text {res }}$ is inhibited, which explains the absence or under-representation of a band co-migrating with diglycosylated $\mathrm{PrP}^{\text {res }}$ in the VPSPr electrophoretic profile [11]. The appearance of a strong diglycosylated band in the amplified product suggests that in PMCA this inhibition effect is overcome and that VPSPr PrP $\mathrm{P}^{\mathrm{Sc}}$ is capable of recruiting and converting diglycosylated and N181 monoglycosylated $\operatorname{PrP}^{\mathrm{C}}$ to a highly proteaseresistant form resembling that found in CJD.

We have also shown for the first time that VPSPr brain homogenate has the potential to seed conversion of recombinant PrP in the RT-QuIC assay. In the single cases that we examined a lower overall efficiency of conversion was observed for VPSPr compared with SCJD of the VV2 subtype. The analysis of a greater number of cases would be necessary to draw definite conclusions on the relative seeding potential of VPSPr versus other human prion disease subtypes. However, different conversion efficiencies between different human prion disease subtypes have been observed previously in RT-QuIC, with variant CJD converting very much less efficiently compared with sCJD [15].

For both VPSPr and sCJD VV2 the RT-QuIC seeding activity was widely dispersed throughout a 10-60\% sucrose gradient, following ultracentrifigation and did not simply reflect the apparent sedimentation of $\mathrm{PrP}^{\text {res }}$ to the lower (more dense) fractions. The sedimentation properties of $\mathrm{PrP}^{\mathrm{Sc}}$ from this VPSPr case 1 showed some similarities to those of sCJD VV2: For sCJD VV2, type 2A PrP ${ }^{\text {res }}$ was predominantly found in the lower (heavier or more dense) fractions. For VPSPr, bands at $\sim 19 \mathrm{kDa}$ and $23 \mathrm{kDa}$, that appeared to co-migrate with the lower and middle bands of type $2 \mathrm{~A} \mathrm{PrP}^{\mathrm{res}}$ in $\mathrm{SCJD}$, were also predominantly found in the lower fractions. However, the $\sim 8 \mathrm{kDa} \operatorname{PrP}^{\text {res }}$ appeared to have different sedimentation properties and was confined to the upper (less dense) fractions. This implies that these two aggregation states (one which is recognised as $\sim 8 \mathrm{kDa} \mathrm{PrP}^{\mathrm{res}}$ and the associated with $\mathrm{PK}$-resistant bands at $\sim 19 \mathrm{kDa}$ and $\sim 23 \mathrm{kDa}$ ) differ in size and exist independently in situ. However, we cannot exclude the possibility that these two different forms might be disaggregated by the mild solubilising effects of the detergent (NOG) needed for SDGC.

The presence of seeding activity in the upper fractions suggests that less dense (presumably smaller) forms of protease sensitive $\mathrm{PrP}^{\mathrm{Sc}}$, possibly including oligomers, can provoke $\mathrm{PrP}^{\mathrm{C}}$ to $\mathrm{PrP}^{\mathrm{Sc}}$ conversion and possibly contribute to the pathogenesis in human prion diseases. It is interesting to note that VPSPr seeding activity was reduced in the uppermost two fractions characterised by $\sim 8 \mathrm{kDa} \operatorname{PrP}^{\text {res. }}$ The fact that $\sim 8 \mathrm{kDa} \mathrm{PrP}^{\text {res }}$ also failed of amplify by PMCA may suggest that the $\operatorname{PrP}^{\mathrm{Sc}}$ conformer associated with $\sim 8 \mathrm{kDa} \operatorname{PrP}^{\text {res }}$ may be an "off pathway" end product of protein misfolding, and perhaps not, as one might suppose an intermediate between fully protease sensitive $\operatorname{PrP}^{\mathrm{Sc}}$ and fully protease resistant $\operatorname{PrP}^{\mathrm{Sc}}$.

VPSPr was first reported in 2008 and to date there are no published studies of its transmissibility to humanised transgenic mouse models. This may be taken to imply that VPSPr is at best poorly transmissible, specifically in comparison to CJD. The data reported here using in vitro 
seeding assays (PMCA and RT-QuIC) seem to suggest that VPSPr transmissibility might be associated with a biochemical profile in VPSPr that partly resembles that found in CJD.

\section{Regional variation of $\mathrm{PrP}^{\mathrm{Sc}}$ abundance and type}

The western blot analysis of regions from VPSPr case 1 showed $\operatorname{PrP}^{\text {res }}$ to be widespread throughout the brain, with the highest levels in the parietal cortex, and the lowest in the medulla and pons. The regional variations of the upper $\sim 19 \mathrm{kDa}$ and $\sim 23 \mathrm{kDa} \operatorname{PrP}^{\mathrm{res}}$ bands and the $\sim 8 \mathrm{kDa} \operatorname{PrP}^{\text {res }}$ band suggest that these subtypes display independent variability according the location within the brain. The degree of difference in the molecular profile of $\mathrm{PrP}^{\mathrm{res}}$ from frontal cortex and cerebellum does however differ between VPSPr cases. This difference was not a major feature of VPSPr case 1, the only case for which we had access to a full range of neuroanatomical regions.

Our study is the first to show a truly widespread distribution of $\operatorname{PrP}^{\text {res }}$ in a VPSPr brain by western blotting. In the original description of VPSPr cases, western blot analysis had been carried out on three subcortical regions (substantia nigra, putamen and thalamus) in eight cases of VPSPr and had found readily detectable amounts of $\operatorname{PrP}^{\text {res }}$ in only one of these subcortical regions (thalamus) from one case [3]. In another case report, $\operatorname{PrP}^{\text {res }}$ was detected by western blotting as a faint ladder-like pattern of bands in cerebral cortex and thalamus and as a $\mathrm{PrP}^{\mathrm{res}}$ pattern resembling the triple band pattern of type $2 \mathrm{~A}$ in cerebellum [9]. Based on the positions of the two immunoreactive bands $(\sim 19$ and $\sim 23 \mathrm{kDa})$ that are apparent in the VPSPr cerebellum of cases 2 and 3 , and all anatomical regions analysed from VPSPr case 1, it is reasonable to conclude that there are molecular overlaps between VPSPr and SCJD: These bands appear to co-migrate with the middle and lower type $2 \mathrm{~A} \mathrm{PrP}^{\mathrm{res}}$ bands (Figure 5 and ref [7]) and have intact C-termini (Additional file 1: Figure S1). However, it should be noted that, in contrast with SCJD VV2, there is a clear under-representation of the upper band.

The western blot results for VPSPr case 1, were reflected in the CDI analysis of the same multiple brain regions from this case. $\mathrm{PrP}^{\mathrm{Sc}}$ (determined on the basis of $\mathrm{D}-\mathrm{N}$ after mild protease treatment) was detected by CDI in the cerebral cortex, midbrain, hippocampus and basal ganglia, but was absent in the medulla. In this VPSPr case, there was a marked reduction, or elimination, of CDI-detectable $\mathrm{PrP}^{\mathrm{Sc}}$ from many regions following treatment with the highest concentration of PK $(50 \mu \mathrm{g} / \mathrm{ml})$, whereas in the parietal cortex $\operatorname{PrP}^{\mathrm{Sc}}$ remained. These results are consistent with the presence of two conformer classes in this case of VPSPr that have either C-terminal $\mathrm{PK}$ resistance (type $2 \mathrm{PrP}^{\mathrm{res}}$ ) or C-terminal PK sensitivity $\left(\sim 8 \mathrm{kDa} \operatorname{PrP}^{\mathrm{res}}\right)$.
The relative conformational stabilities of $\operatorname{PrP}^{\mathrm{Sc}}$ from different regions from VPSPr case 1 were also determined by centrifugal concentration of $\operatorname{PrP}^{\mathrm{Sc}}$, and the resuspension and denaturation of the pellet with a range of $\mathrm{GdnHCl}$ concentrations. We have shown that in the absence of $\mathrm{PK}$, CDI-detectable $\mathrm{PrP}^{\mathrm{Sc}}$ can be recovered from VPSPr homogenates by virtue of sarkosyl insolubility and following resuspension and unfolding in various concentrations of $\mathrm{GdnHCl}$ a sigmoidal transition is seen for all VPSPr regions and the GSS and sCJD VV2 subtype positive controls. Differential $\operatorname{PrP}^{\mathrm{Sc}}$ stability was marked in VPSPr case 1, consistent with different forms or mixtures of forms present in different regions.

A marked difference in conformational $\operatorname{PrP}^{\mathrm{Sc}}$ stability was seen between VPSPr cerebral cortex and cerebellum with cerebellar $\operatorname{PrP}^{\mathrm{Sc}}$ being apparently much more stable and a $[\mathrm{GdnHCl}]^{1 / 2}$ of $\sim 3.6 \mathrm{M}$. In contrast, in the sCJD VV2 subtype case we have shown that a marginally lower stability $\left([\mathrm{GdnHCl}] \frac{1}{2} \sim 1.9\right.$ ) is obtained for cerebellum compared with frontal cortex ( 2.4) (Table 3 and Additional file 1: Figure S3). No difference in stability was observed between the frontal cortex and cerebellum for cases of GSS (type $1 \operatorname{PrP}^{\text {res }}$ ) and previous studies failed to detect a marked difference in $\operatorname{PrP}^{\mathrm{Sc}}$ stability between these regions in GSS [21] and variant CJD [12].

The co-existence of distinct $\operatorname{PrP}^{\mathrm{res}}$ types (1 and $2 \mathrm{~A}$ ) has been noted in a significant proportion of sporadic CJD brains by western blotting [22,23]. Using an alternative method to CDI, known as conformational stability immunoassay (CSI) Cali et al have reported different stabilities for type 1 versus type $2 \mathrm{~A} \mathrm{PrP}^{\text {res }}$ in individuals who are MM at PRNP-codon-129. In MM cases with coexistent $\operatorname{PrP}^{\text {res }}$ types a spectrum of $\operatorname{PrP}^{\mathrm{Sc}}$ stabilities were obtained with values that spanned the region between the stabilities reported for (non-mixed) type 1 and type 2A $\mathrm{PrP}^{\text {res }}$ sCJD cases [22]. However, our study is the first to report a marked difference in $\operatorname{PrP}^{\mathrm{Sc}}$ stability between two anatomical regions of the same prion disease brain and provides further evidence for the existence of $\mathrm{PrP}^{\mathrm{Sc}}$ heterogeneity in VPSPr brains.

\section{The relationship of VPSPr to GSS}

A similarity had been noted between GSS and VPSPr, in terms of the $\mathrm{PrP}^{\text {res }}$ electrophoretic profile and the relative sensitivities of $\mathrm{PrP}^{\text {res }}$ fragments within these profiles to digestion with PK $[4,24]$. This has led to suggestions that VPSPr is the sporadic equivalent of GSS, in the same way that sporadic fatal insomnia (sCJD MM2-Thalamic) has been proposed to be the sporadic equivalent of fatal familial insomnia (PRNP D178N Codon-129M). Pirisinu et al. examined the relationship between VPSPr and GSS in humans and an atypical form of scrapie in sheep and goats known as Nor98 [21]. They also compared the conformation stabilities of $\mathrm{PrP}^{\mathrm{Sc}}$ from a single brain region 
(frontal cortex) of VPSPr and GSS patients, using an alternative method to CDI, known as conformational stability and solubility assay (CSSA) that measures the diminution of $\operatorname{PrP}^{\mathrm{Sc}}$ remaining in the detergent insoluble pellet after treatment with increasing concentrations of $\mathrm{GdnHCl}$. In agreement with our study, Pirisinu et al determined the $\mathrm{PrP}^{\mathrm{Sc}}$ stability in VPSPr frontal cortex (PRNP-codon 129 VV) to be $[\mathrm{GdnHCl}]^{1 / 2}=2.0-2.4 \mathrm{M}[21]$ which they showed to be midway between the $\operatorname{PrP}^{\mathrm{Sc}}$ stabilities in GSS P102L (type $\left.1+\sim 8 \mathrm{kDa} \operatorname{PrP}{ }^{\text {res }}\right)$ and GSS P102L $\left(\sim 8 \mathrm{kDa} \operatorname{Pr} \mathrm{P}^{\text {res }}\right)$.

Our current study and the study by Pirisinu et al. indicate that the biochemical characteristics of $\mathrm{PrP}^{\mathrm{Sc}}$ from the VPSPr cases did not exactly match the $\operatorname{PrP}^{\mathrm{Sc}}$ phenotypes observed in GSS, and therefore suggest that VPSPr is a distinct biochemical entity. A key distinction we observed in this study is the differing conformational stabilities of VPSPr PrP ${ }^{\mathrm{Sc}}$ between cerebral cortex and cerebellum and no such difference in $\operatorname{PrP}^{\mathrm{Sc}}$ stabilities was observed for a case of GSS P102L (type $1 \operatorname{PrP}^{\text {res}}$ ) (Table 3). PrP ${ }^{\mathrm{Sc}}$ from VPSPr cerebellum is considerably more stable, and in a number of VPSPr cases it is associated with $\mathrm{PrP}^{\text {res }}$ bands on western blot analysis, that appear to co-migrate with type $2 \operatorname{PrP}^{\text {res }}$ bands observed in sCJD. In contrast, $\operatorname{PrP}^{\mathrm{Sc}}$ from VPSPr cerebral cortex has a stability and $\operatorname{PrP}^{\text {res }}$ molecular profile that is closer to GSS $\sim 8 \mathrm{kDa} \operatorname{PrP}^{\text {res }}$ cases.

\section{Conclusions}

Our analyses indicate the following: Firstly, CDI confirms the presence of readily detectable $\operatorname{PrP}^{\mathrm{Sc}}$ in VPSPr that can be diminished by mild protease treatment. However, CDI also demonstrates that a proportion of the $\mathrm{PrP}^{\mathrm{Sc}}$ found in VPSPr resists digestion of its Cterminus even when high concentrations of protease are used. This characteristic distinguishes VPSPr from GSS associated with $\sim 8 \mathrm{kDa} \operatorname{PrP}^{\text {res }}$ and points to biochemical similarities with SCJD. Some, but not all cases of VPSPr show in the cerebellum $\operatorname{PrP}^{\text {res }}$ bands at $\sim 19$ and $\sim 23 \mathrm{kDa}$ that co-migrate with the lower and middle bands of type $2 \mathrm{~A} \mathrm{PrP}^{\text {res }}$ in SCJD, instead of, or in addition to, the $\sim 8 \mathrm{kDa}$ type. It is the former type that appears to replicate in PMCA. In contrast, little or no amplification was observed for the $\sim 8 \mathrm{kDa} \operatorname{PrP}^{\text {res }}$ either in VPSPr or a case of GSS associated with this $\mathrm{PrP}^{\text {res }}$ subtype.

Intensive investigation of a single VPSPr case showed broad brain region-specific spectrum of protease sensitivity, differing relative amounts of $\sim 8 \mathrm{kDa} P r P^{\text {res }}$ and $\sim 19 \& 23 \mathrm{kDa} \operatorname{PrP}^{\mathrm{res}}$, and the stability of $\operatorname{PrP}^{\mathrm{Sc}}$ in the absence of proteases depending on the brain region examined. $\operatorname{PrP}^{\mathrm{Sc}}$ was found to be widely distributed throughout cortical and some subcortical brain regions in VPSPr. The sedimentation properties and RT-QuIC seeding activity of $\operatorname{PrP}^{\mathrm{Sc}}$ from VPSPr frontal cortex resemble those of CJD.
The overall conclusion of this study is that VPSPr is heterogeneous in terms of protease sensitivity and resistance to denaturation by chaotropes and includes a proportion of $\operatorname{PrP}^{\mathrm{Sc}}$ with biochemical properties and functional characteristics similar to those of sCJD. This heterogeneity exists both between VPSPr cases and between brain regions within individual cases. Although this study has focussed on the biochemical aspects of $\mathrm{PrP}^{\mathrm{Sc}}$ in VPSPr, the heterogeneity that we have observed may party underlie the neuropathological heterogeneity in VPSPr cases.

\section{Additional file}

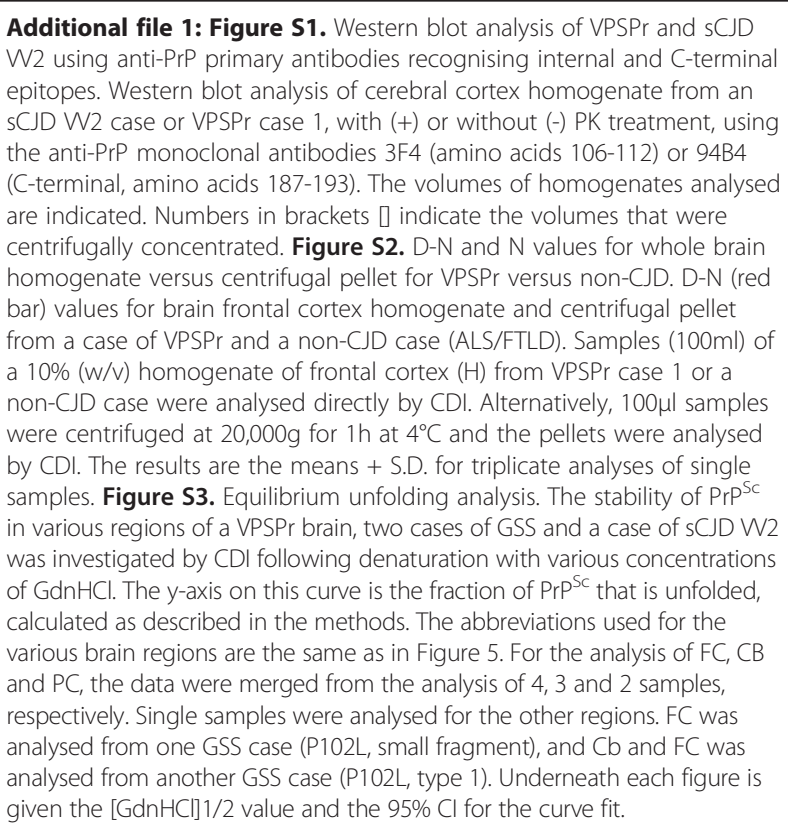

Competing interests

The authors declare that they have no competing interests.

\section{Authors' contributions}

AHP, planned and executed the experiments working with the other authors, and drafted the manuscript; DPS, performed CDI analysis of both PrPSC sensitivity and stability and helped draft the manuscript, CRM performed the SDGC and RT-QulC analysis and helped draft the manuscript; MAB performed the PMCA experiments. DLR performed the histological and neuropathological analysis; JWI performed neuropathological analysis, oversaw the study and reviewed and edited the manuscript. MWH conceived of the study, and participated in its design and coordination and helped to draft the manuscript. All authors read and approved the final manuscript.

\section{Acknowledgments}

The NCJDRSU is supported by the Department of Health, England and the Scottish Government. This report is independent research commissioned and funded by the Department of Health Policy Research Programme (Genetic risk factors and other characteristics which contribute to pathogenesis in human prion diseases including variant CJD, PR-ST-1213-00006). The views expressed in this publication are those of the authors and not necessarily those of the Department of Health. Deep Sarode was in receipt of a Welcome Trust Biomedical Vacation Scholarship. Tissue specimens were obtained from the Edinburgh Brain \& Tissue Bank (11/ES/0022), which is supported by the Medical Research Council (MRC G0900580). We thank 
Dr Albrecht Gröner, (CSL Behring, Marburg, Germany), for provision of MAR-1 antibody, Dr Dave Jackson and Dr Gary Mallinson (NHS Blood and Transplant, Bristol, UK) for the provision of recombinant PrP and Dr Rona Barron and Professor Jean Manson for provision of humanised transgenic mouse brain tissues. We would like to thank the relatives of patients for the opportunity to conduct research on tissue specimens. We are grateful to all Neuropathologists and their Technical Staff in the UK who support the work of NCJDRSU.

Received: 11 September 2014 Accepted: 10 October 2014

Published online: 21 October 2014

\section{References}

1. Parchi P, Castellani R, Capellari S, Ghetti B, Young K, Chen SG, Farlow M, Dickson DW, Sima AA, Trojanowski JQ, Petersen RB, Gambetti P (1996) Molecular basis of phenotypic variability in sporadic Creutzfeldt-Jakob disease. Ann Neurol 39:767-778

2. Piccardo P, Dlouhy SR, Lievens PM, Young K, Bird TD, Nochlin D, Dickson DW, Vinters HV, Zimmerman TR, Mackenzie IR, Kish SJ, Ang LC, De CC, Pocchiari M, Brown P, Gibbs CJ Jr, Gajdusek DC, Bugiani O, Ironside J, Tagliavini F, Ghetti B (1998) Phenotypic variability of Gerstmann-Straussler-Scheinker disease is associated with prion protein heterogeneity. J Neuropathol Exp Neurol 57:979-988

3. Gambetti P, Dong Z, Yuan J, Xiao X, Zheng M, Alshekhlee A, Castellani R, Cohen M, Barria MA, Gonzalez-Romero D, Belay ED, Schonberger LB, Marder K, Harris C, Burke JR, Montine T, Wisniewski T, Dickson DW, Soto C, Hulette CM, Mastrianni JA, Kong Q, Zou WQ (2008) A novel human disease with abnormal prion protein sensitive to protease. Ann Neurol 63:697-708

4. Zou WQ, Puoti G, Xiao X, Yuan J, Qing L, Cali I, Shimoji M, Langeveld JP, Castellani R, Notari S, Crain B, Schmidt RE, Geschwind M, DeArmond SJ, Cairns NJ, Dickson D, Honig L, Torres JM, Mastrianni J, Capellari S, Giaccone G, Belay ED, Schonberger LB, Cohen M, Perry G, Kong Q, Parchi P, Tagliavini F, Gambetti P (2010) Variably protease-sensitive prionopathy: a new sporadic disease of the prion protein. Ann Neurol 68:162-172

5. Head MW, Knight R, Zeidler M, Yull H, Barlow A, Ironside JW (2009) A case of protease sensitive prionopathy in a patient in the UK. Neuropathol Appl Neurobiol 35:628-632

6. Head MW, Lowrie S, Chohan G, Knight R, Scoones DJ, Ironside JW (2010) Variably protease-sensitive prionopathy in a PRNP codon 129 heterozygous UK patient with co-existing tau, alpha synuclein and Abeta pathology. Acta Neuropathol 120:821-823

7. Head MW, Yull HM, Ritchie DL, Langeveld JP, Fletcher NA, Knight RS, Ironside JW (2013) Variably protease-sensitive prionopathy in the UK: a retrospective review 1991-2008. Brain 136:1102-1115

8. Jansen C, Head MW, van Gool WA, Baas F, Yull H, Ironside JW, Rozemuller AJ (2010) The first case of protease-sensitive prionopathy (PSPr) in The Netherlands: a patient with an unusual GSS-like clinical phenotype. J Neurol Neurosurg Psychiatry 81:1052-1055

9. Rodriguez-Martinez AB, Garrido JM, Zarranz JJ, Arteagoitia JM, de Pancorbo MM, Atares B, Bilbao MJ, Ferrer I, Juste RA (2010) A novel form of human disease with a protease-sensitive prion protein and heterozygosity methionine/valine at codon 129: Case report. BMC Neurol 10:99

10. Rodriquez-Martinez AB, de Munain AL, Ferrer I, Zarranz JJ, Atares B, Villagra NT, Arteagoitia JM, Garrido JM, Juste RA (2012) Coexistence of protease sensitive and resistant prion protein in $129 \mathrm{~W}$ homozygous sporadic Creutzfeldt-Jakob disease: a case report. J Med Case Rep 6:348

11. Xiao X, Yuan J, Haik S, Cali I, Zhan Y, Moudjou M, Li B, Laplanche JL, Laude H, Langeveld J, Gambetti P, Kitamoto T, Kong Q, Brandel JP, Cobb BA, Petersen RB, Zou WQ (2013) Glycoform-selective prion formation in sporadic and familial forms of prion disease. PLoS One 8:e58786

12. Choi YP, Peden AH, Groner A, Ironside JW, Head MW (2010) Distinct stability states of disease-associated human prion protein identified by conformation-dependent immunoassay. J Virol 84:12030-12038

13. Choi YP, Groner A, Ironside JW, Head MW (2011) Comparison of the level, distribution and form of disease-associated prion protein in variant and sporadic Creutzfeldt-Jakob diseased brain using conformation-dependent immunoassay and Western blot. J Gen Virol 92:727-732

14. Safar JG, Geschwind MD, Deering C, Didorenko S, Sattavat M, Sanchez H, Serban A, Vey M, Baron H, Giles K, Miller BL, DeArmond SJ, Prusiner SB (2005) Diagnosis of human prion disease. Proc Natl Acad Sci U S A 102:3501-3506
15. Peden AH, McGuire LI, Appleford NE, Mallinson G, Wilham JM, Orru CD, Caughey B, Ironside JW, Knight RS, Will RG, Green AJ, Head MW (2012) Sensitive and specific detection of sporadic Creutzfeldt-Jakob disease brain prion protein using real-time quaking-induced conversion. J Gen Virol 93:438-449

16. Lee DC, Stenland CJ, Hartwell RC, Ford EK, Cai K, Miller UL, Gilligan KJ, Rubenstein R, Fournel M, Petteway SR Jr (2000) Monitoring plasma processing steps with a sensitive Western blot assay for the detection of the prion protein. J Virol Methods 84:77-89

17. Yull HM, Ritchie DL, Langeveld JP, van Zijderveld FG, Bruce ME, Ironside JW, Head MW (2006) Detection of type 1 prion protein in variant Creutzfeldt-Jakob disease. Am J Pathol 168:151-157

18. Barria MA, Balachandran A, Morita M, Kitamoto T, Barron R, Manson J, Knight R, Ironside JW, Head MW (2014) Molecular barriers to zoonotic transmission of prions. Emerg Infect Dis 20:88-97

19. Yokoyama T, Takeuchi A, Yamamoto M, Kitamoto T, Ironside JW, Morita M (2011) Heparin enhances the cell-protein misfolding cyclic amplification efficiency of variant Creutzfeldt-Jakob disease. Neurosci Lett 498:119-123

20. Saverioni D, Notari S, Capellari S, Poggiolini I, Giese A, Kretzschmar HA, Parchi P (2013) Analyses of protease resistance and aggregation state of abnormal prion protein across the spectrum of human prions. J Biol Chem 288:27972-27985

21. Pirisinu L, Nonno R, Esposito E, Benestad SL, Gambetti P, Agrimi U, Zou WQ (2013) Small ruminant nor98 prions share biochemical features with human gerstmann-straussler-scheinker disease and variably protease-sensitive prionopathy. PLoS One 8:e66405

22. Cali I, Castellani R, Alshekhlee A, Cohen Y, Blevins J, Yuan J, Langeveld JP, Parchi P, Safar JG, Zou WQ, Gambetti P (2009) Co-existence of scrapie prion protein types 1 and 2 in sporadic Creutzfeldt-Jakob disease: its effect on the phenotype and prion-type characteristics. Brain 132:2643-2658

23. Head MW, Bunn TJ, Bishop MT, McLoughlin V, Lowrie S, McKimmie CS, Williams MC, McCardle L, Mackenzie J, Knight R, Will RG, Ironside JW (2004) Prion protein heterogeneity in sporadic but not variant Creutzfeldt-Jakob disease: U.K. cases 1991-2002. Ann Neurol 55:851-859

24. Piccardo P, Liepnieks JJ, William A, Dlouhy SR, Farlow MR, Young K, Nochlin D, Bird TD, Nixon RR, Ball MJ, DeCarli C, Bugiani O, Tagliavini F, Benson MD, Ghetti B (2001) Prion proteins with different conformations accumulate in Gerstmann-Straussler-Scheinker disease caused by A117V and F198S mutations. Am J Pathol 158:2201-2207

doi:10.1186/s40478-014-0152-4

Cite this article as: Peden et al.: The prion protein protease sensitivity, stability and seeding activity in variably protease sensitive prionopathy brain tissue suggests molecular overlaps with sporadic Creutzfeldt-Jakob disease. Acta Neuropathologica Communications 2014 2:152.

\section{Submit your next manuscript to BioMed Central and take full advantage of:}

- Convenient online submission

- Thorough peer review

- No space constraints or color figure charges

- Immediate publication on acceptance

- Inclusion in PubMed, CAS, Scopus and Google Scholar

- Research which is freely available for redistribution 